\title{
If you build it, will they come? Kenya healthy start pediatric HIV study: A diagnostic study investigating barriers to HIV treatment and care among children
}

\author{
Karusa Kiragu \\ Population Council \\ Katie D. Schenk \\ Population Council \\ Julie Murugi \\ Population Council \\ Avina Sarna \\ Population Council
}

Follow this and additional works at: https://knowledgecommons.popcouncil.org/departments_sbsr-hiv

Part of the Demography, Population, and Ecology Commons, Health Policy Commons, Immune System Diseases Commons, International Public Health Commons, Maternal and Child Health Commons, Medicine and Health Commons, Public Health Education and Promotion Commons, Virus Diseases Commons, and the Women's Health Commons How does access to this work benefit you? Let us know!

\section{Recommended Citation}

Kiragu, Karusa, Katie D. Schenk, Julie Murugi, and Avina Sarna. 2008. "If you build it, will they come? Kenya healthy start pediatric HIV study: A diagnostic study investigating barriers to HIV treatment and care among children," Horizons Final Report. Washington, DC: Population Council. 


\section{Hqrizons}

"If You Build It, Will They Come?"

Kenya Healthy Start Pediatric HIV Study:

A Diagnostic Study Investigating Barriers to HIV Treatment and Care among Children
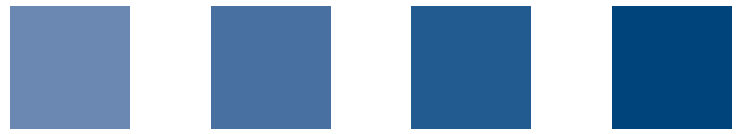

Horizons Program 


\section{"If You Build It, Will They Come?" Kenya Healthy Start Pediatric HIV Study: A Diagnostic Study Investigating Barriers to HIV Treatment and Care Among Children}

Karusa Kiragu, Katie Schenk, Julie Murugi, and Avina Sarna, Horizons/Population Council

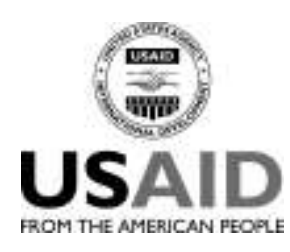

\section{Hgrizons}
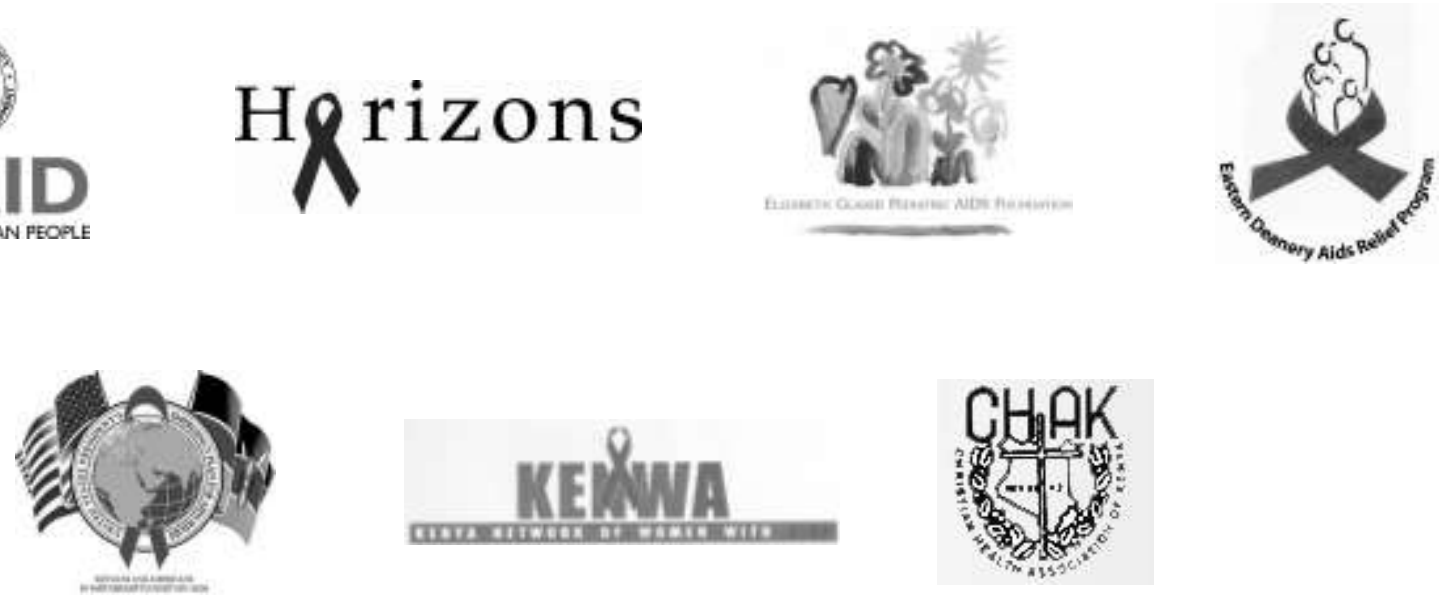


\section{Acknowledgments}

The principal investigators for this Horizons research study were Karusa Kiragu, Avina Sarna, and Katie Schenk (Horizons/Population Council Nairobi, New Delhi, and Washington DC). Research team members responsible for protocol development, fieldwork management, and data management were Julie Murugi, Murungaru Kimani, George Odingo, and Scott Geibel (Horizons/Population Council Nairobi). Data collection team members are listed in the Appendix.

The research team would like to thank the collaborating partners at each of the study sites for their support of this study and active input: Peter Savosnick, John Odero Ong'ech, and Judy Kose-Otieno (Elizabeth Glaser Pediatric AIDS Foundation); Father Ed Phillips and George Owiso (Eastern Deanery AIDS Relief Program); Peter Ngure (Christian Health Association of Kenya); and Ann Wacuka and Asunta Wagura (Kenya Network of Women with AIDS).

The research team is grateful to the Project Advisory Committee for valuable guidance throughout the study: Peter Cherutich (NASCOP), Irene Inwani (University of Nairobi), and Margaret Makonyango (University of Nairobi).

The research team is especially grateful to the community members who generously gave their time to participate in this research by responding to the household questionnaires and sharing personal experiences and viewpoints in the focus groups. Special thanks also go to the hospital management, health care workers, and community health workers who participated in this study, for their exceptional contributions. The authors are grateful to the United States Agency for International Development and the President's Emergency Plan for AIDS Relief for providing funding support for this study.

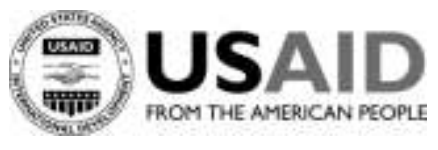

This study and final report were made possible by the President's Emergency Plan for AIDS Relief and the generous support of the American people through the United States Agency for International Development (USAID) under the terms of Cooperative Agreement No. HRN-A00-97-00012-00. The contents are the responsibility of the Horizons Program and do not necessarily reflect the views of USAID or the United States Government.

Published in June 2008.

\section{(2) Population Council}

The Population Council is an international, non-profit, nongovernmental institution that seeks to improve the well-being and reproductive health of current and future generations around the world and to help achieve a humane, equitable, and sustainable balance between people and resources. The Council conducts biomedical, social science, and public health research and helps build research capacities in developing countries. Established in 1952, the Council is governed by an international board of trustees. Its New York headquarters supports a global network of regional and country offices.

Copyright (C) 2008. The Population Council Inc.

Suggested citation: Kiragu, Karusa, Katie Schenk, Julie Murugi and Avina Sarna. 2008. “'If you build it, will they come?' Kenya healthy start pediatric HIV study: A diagnostic study investigating barriers to HIV treatment and care among children," Horizons Final Report. Washington, DC: Population Council.

This document may be reproduced in whole or in part without permission of the Population Council provided full source citation is given and the reproduction is not for commercial purposes. 


\section{Table of Contents}

\section{Abbreviations and Acronyms}

$\begin{array}{ll}\text { Executive Summary } & 1\end{array}$

$\begin{array}{lr}\text { Introduction } & 4\end{array}$

Background $\quad 4$

Study aims, objectives, and research questions $\quad 5$

$\begin{array}{ll}\text { Study partners and sites } & 6\end{array}$

$\begin{array}{lr}\text { Methods } & 8\end{array}$

$\begin{array}{ll}\text { Qualitative methods } & 8\end{array}$

$\begin{array}{ll}\text { Quantitative methods } & 9\end{array}$

Ethical clearance and approvals $\quad 11$

$\begin{array}{ll}\text { Study limitations } & 11\end{array}$

$\begin{array}{ll}\text { Results } & 12\end{array}$

Community sociodemographic profile $\quad 12$

Health-seeking behaviors $\quad 15$

$\begin{array}{ll}\text { Quality of care } & 19\end{array}$

Practical barriers to care: cost, distance, and time $\quad 25$

Knowledge about HIV and AIDS $\quad 28$

HIV testing and status disclosure $\quad 31$

Pediatric antiretroviral treatment 36

Attitudinal barriers to accessing care $\quad 41$

HIV among older children $\quad 46$

$\begin{array}{ll}\text { Facility barriers } & 48\end{array}$

$\begin{array}{ll}\text { Discussion } & 54\end{array}$

Barriers to pediatric HIV care $\quad 54$

Programmatic recommendations $\quad 59$

$\begin{array}{ll}\text { Next steps: Intervention development } & 60\end{array}$ 
$\begin{array}{ll}\text { References } & 61\end{array}$

Appendix: Data Collectors and Supervisors $\quad 62$ 


\section{Abbreviations and Acronyms}

$\begin{array}{ll}\text { AIDS } & \text { acquired immune deficiency syndrome } \\ \text { ANC } & \text { antenatal care } \\ \text { ART } & \text { antiretroviral therapy } \\ \text { ARV } & \text { antiretroviral } \\ \text { CHAK } & \text { Christian Hospitals Association of Kenya } \\ \text { CHW } & \text { community health worker } \\ \text { DHMT } & \text { District Health Management Team } \\ \text { EA } & \text { enumeration area } \\ \text { EDARP } & \text { Eastern Deanery AIDS Relief Program } \\ \text { EGPAF } & \text { Elizabeth Glaser Pediatric AIDS Foundation } \\ \text { FGD } & \text { focus group discussion } \\ \text { FP } & \text { family planning } \\ \text { HIV } & \text { human immunodeficiency virus } \\ \text { HW } & \text { health worker } \\ \text { IDI } & \text { in-depth interview } \\ \text { IMCI } & \text { integrated management of childhood illness } \\ \text { KENWA } & \text { Kenya Network of Women Living With AIDS } \\ \text { MCH } & \text { Maternal and child health } \\ \text { NASCOP } & \text { National AIDS and STD Control Program [Kenya] } \\ \text { OI } & \text { opportunistic infection } \\ \text { PCR } & \text { polymerase chain reaction } \\ \text { PEPFAR } & \text { President's Emergency Plan for AIDS Relief } \\ \text { PLHIV } & \text { Person/people living with HIV } \\ \text { PMTCT } & \text { prevention of mother-to-child transmission } \\ \text { TB } & \text { tuberculosis } \\ \text { VCT } & \text { voluntary counseling and testing } \\ \text { WHO } & \text { World Health Organization } \\ & \end{array}$





\section{Executive Summary}

\section{Background}

Supply-side barriers restricting pediatric antiretroviral therapy (ART) access in sub-Saharan Africa are documented, but less is known about demand-side barriers, especially the health-seeking behaviors of parents and guardians on behalf of young children. Evidence suggests low uptake of pediatric ART where it is available, even in high prevalence areas, indicating that availability alone does not ensure that people are utilizing treatment services.

In Kenya, while nearly half of the HIV-positive adults who need treatment are already receiving it, the proportion of eligible children receiving treatment is only 11 percent (Cherutich 2006; Koech 2006). This study explored and documented possible barriers in the community to accessing pediatric HIV testing and treatment in Kenya, to guide the development of new interventions to encourage uptake.

\section{Methodology}

Horizons conducted research in the catchment areas of six facilities offering pediatric HIV services in Nairobi, Eastern, and Nyanza provinces, Kenya. This included a population-based survey among households with children under age 15 years located within five kilometers of the facilities $(\mathrm{n}=1,182,52$ percent female). Complementary qualitative and quantitative methods included focus group discussions (FGDs) and interviews with health workers, facility managers, and members of support groups for people living with HIV (PLHIV), and a health worker survey that included nurses, counselors, clinical officers, and doctors $(\mathrm{n}=97)$.

\section{Key Findings}

\section{Cost is a barrier to pediatric HIV treatment}

Although the Kenyan government provides free ART, clients bear additional costs including transport, consultation fees, and medications to treat opportunistic infections. With attendees reporting that the mean total cost of a single clinic visit exceeds KShs $400^{1}$, cost remains a major access barrier to pediatric treatment. Research participants reported that they had delayed or deferred care for their children as a result of the costs involved.

\section{Caregivers often turn to traditional healers}

While nearly all household survey respondents said that they had utilized modern medical clinic facilities, FGDs revealed considerable use of traditional and faith healers, especially in Nyanza and Eastern provinces. Caregivers often sought pediatric medical care only after exhausting traditional options. As a result, increased morbidity and mortality was often interpreted as a reflection on clinical care,

\footnotetext{
${ }^{1} \mathrm{US} \$ 1=\mathrm{KSh} 67$
} 


\section{Hgrizons}

perpetuating myths about the ineffectiveness of clinic services. Health care providers were sometimes unsure of how to respond to clients who utilized both traditional and modern clinical care.

\section{Caregivers demonstrate low knowledge of pediatric HIV and treatment options}

Knowledge of HIV transmission, indications for testing, and local treatment options were limited, and misconceptions prevailed. Only half of survey respondents could name three or more indications of a child who should be referred for HIV testing. Further, only 64 percent of children's caregivers surveyed were aware of nearby pediatric HIV facilities, and only half of respondents were aware that pediatric antiretrovirals (ARVs) are a lifelong commitment.

\section{Attitudinal barriers to pediatric treatment are widespread}

Attitudinal barriers including fear and losing hope deter caregivers from seeking pediatric HIV care. The widespread belief that an HIV-positive child is a "lost cause" persists. Fatalistic attitudes equate HIV with death, especially among children, and respondents reported widespread reluctance to invest resources in such children.

\section{Stigma prevents caregivers from seeking pediatric HIV care}

HIV-related stigma further contributes to avoidance and denial. Many caregivers - especially mothersexpressed fear that being known to have an HIV-positive child would reveal their own serostatus, exposing them to allegations of promiscuity or unfaithfulness, and forcing them to acknowledge their own health risks. Stigma was cited as one of the main reasons that HIV-positive parents had delayed seeking care, as it impedes their ability to disclose their HIV status (including permitting home visits from community health workers) and to seek care for their children.

\section{Older children and adolescents face unique treatment issues}

With the first generation of perinatally-infected children now surviving into adolescence and beyond, a new range of treatment issues must be addressed. These include managing treatment at school and negotiating friendships, sexual relationships, and future planning - all while coping with the psychosocial complexities of adolescence. Among survey participants, 36 percent said that HIV-positive children aged 7-15 years should be told their serostatus. Caregivers reported difficulties communicating with adolescents about issues of treatment, adherence, and sexual behavior, and called for youth-friendly services to respond to the care and treatment needs of adolescents on ART.

\section{Caregivers cite dissatisfaction with HIV services received}

Across all three provinces 18 percent of respondents who had visited catchment facilities expressed dissatisfaction with services, mostly due to lack of drugs, negative provider attitudes, long waits, and cost. Respondents described the reproachful and accusatory attitudes of heath workers toward the parents of sick children, and their unwillingness to listen to clients or to let them ask questions. 


\section{Health workers miss opportunities to discuss pediatric HIV with clients}

With limited community knowledge about pediatric HIV and available services, antenatal care can provide opportunities for communication between health providers and mothers during a time when women may be particularly receptive. However, the community survey indicated that for about a quarter of female respondents with children under age five who received antenatal care at last pregnancy, prevention of mother-to-child transmission (PMTCT) had not been discussed.

\section{Health workers cite service-side challenges}

The health workers' survey revealed gaps in HIV knowledge and low confidence in pediatric HIV diagnosis protocols, drug management, and counseling. Further challenges hampering service delivery included space constraints, staff shortages, and unreliable systems for communicating with laboratories, resulting in long waits for consultations, limited privacy, and long delays in receiving test results. These challenges reduce health workers' capacity to offer quality care, resulting in negative community perceptions, and further increasing community barriers to uptake.

\section{Next steps}

In wealthy countries, pediatric HIV is largely under control, mostly because of effective PMTCT programs as well as accessible diagnostic testing and ART. It is also important that for the health care service delivery system to recognize that HIV-positive children are not smaller versions of their adult counterparts; they have unique needs, and if untreated, disease progression among them can be rapid and aggressive. In Kenya, many obstacles to providing pediatric HIV management exist, starting with a weak service delivery system for uninformed and strained caregivers. Based on this study, Horizons will work with the study partners to implement appropriate interventions to respond to the problems identified by the research. The following priorities will be explored:

- Implementing community awareness activities to educate and support caregivers, to inform them about available services and to reduce stigma.

- Bringing services closer to the people, for example through mobile clinics and utilization of trained community health workers.

- Strengthening the capacity of health care workers so that they can provide quality care and appropriate referrals.

- Supporting family-based HIV testing approaches so that HIV-positive family members can be identified and offered timely care.

- Utilizing strategies to reach HIV-positive adolescents and young adults. 


\section{Hgrizons}

\section{Introduction}

\section{Background}

\section{Pediatric HIV}

AIDS is one of the leading causes of mortality and morbidity among children in sub-Saharan Africa. Without access to antiretroviral therapy (ART), about 50 percent of children infected with HIV at birth die by their second birthday (UNICEF 2005). In 2005, there were 2 million children under the age of 15 years living with HIV in sub-Saharan Africa, 470,000 new HIV infections among children, and 300,000 AIDS-related deaths among children (UNAIDS 2006). In Kenya, it is estimated that 20,000-30,000 children acquire HIV annually, and that there are now 120,000-150,000 infected children (Cherutich 2006).

In this context, pediatric HIV infection is defined as infection among children aged younger than 15 years. Most pediatric HIV infections are acquired perinatally, during pregnancy, birth, or breastfeeding. However, young adolescents - especially females - are also at risk of HIV infection through sexual transmission. According to the KDHS, 14 percent of female youth and 29 percent of male youth have had sex by the age of 15 (Central Bureau of Statistics [Kenya], Ministry of Health [Kenya] et al. 2004). The elevated vulnerability of young women to HIV acquisition is well documented and is fueled by biological and socioeconomic factors (UNAIDS 2006).

\section{Efficacy and availability of pediatric treatment}

A growing body of research documents the efficacy of highly active antiretroviral treatment (HAART) among children, which suppresses viral replication to improve long-term survival (Watson and Farley 1999; Eley, Nuttall et al. 2004; van Kooten Niekerk, Knies et al. 2006). Emerging data from studies in South Africa, Zambia, and Brazil demonstrate that ART is effective in decreasing pediatric morbidity and mortality, even in settings where the health infrastructure is relatively limited (Matida, Novaes et al. 2006; Mbewe, Bolton et al. 2006; Olson, Sauvageot et al. 2006). Interventions that can improve the quality of life for children living with HIV, even in the absence of ART, include growth monitoring and nutritional interventions. Infants whose HIV status is unknown but whose mothers are known to be HIV-positive and who are showing acute signs of illness can benefit from presumptive cotrimoxazole prophylaxis and treatment of opportunistic infections (OI), as well as from emotional support for both child and caregiver (ANECCA 2005; NASCOP 2005a). In Kenya, the Guidelines for Antiretroviral Drug Therapy (NASCOP 2005b) synthesize the international evidence to make country-specific recommendations addressing the specific diagnosis, staging, and treatment needs for children exposed to HIV. These guidelines are presently being updated to include pediatric ART.

Despite the evidence, treatment of children who are HIV-positive remains a neglected priority. Globally, children made up 6 percent of people living with HIV in 2005, and accounted for 14 percent of AIDSrelated deaths. According to UNICEF, less than 5 percent of children who need ART are receiving it (Luo 2005). While World Health Organization (WHO) targets specify that 10 percent of patients on ART should be children, few programs are meeting this target: a survey of HIV treatment programs conducted by the Global AIDS Alliance found that children make up only 3.6 percent of all people receiving ART worldwide (deGennaro and Zeitz 2005). 


\section{ART program in Kenya}

Increasing affordability of ART and the demonstrated feasibility of administering these drugs has resulted in scaling up access to treatment among adults in Kenya. National treatment initiatives have been supported by international efforts, including PEPFAR, which has committed to spend approximately USD $\$ 15$ billion to prevent 7 million new HIV infections, treat 2 million people with HIV, and care for 10 million HIV-infected persons and those orphaned by AIDS (Office of the United States Global AIDS Coordinator 2004) and WHO's 3 by 5 initiative (World Health Organization 2003). Adults in Kenya have begun to benefit from the recent expansion of treatment programs under these government and donorfunded treatment initiatives: in Kenya, almost 90,000 people (43 percent of those eligible) are currently estimated to be on ART (Koech 2006). The Government of Kenya is committed to expanding treatment to cover 75 percent of eligible patients by the end of 2008, by offering comprehensive care through the national network of health facilities (NASCOP 2005b).

Pediatric treatment lags far behind adult treatment: while 40 percent of adults in need of treatment are now receiving it, only 11 percent of children in Kenya who need it are currently on this life-saving therapy (Cherutich 2006; Koech 2006). Only 168 of the 261 sites providing adult AIDS treatment also provide pediatric treatment (Koech, 2006). This gap is evident in the nation's high pediatric mortality: approximately one-third of infant deaths can be attributed to AIDS (NASCOP 2005a).

HIV testing in children is a new initiative in Kenya, and providers are now encouraged to test all children whose HIV status is unknown (NASCOP/CDC 2006), including both exposed and unexposed children. A new sensitization campaign to encourage parents to get their children tested for HIV was launched in October 2007 under the name of "Niruhusu Niishi" ("Let me live").

\section{Study Aims, Objectives, and Research Questions}

\section{Study aims}

This study aimed to examine barriers to uptake of pediatric HIV care and treatment services, including community perceptions and service quality, to derive lessons for increasing uptake of existing services.

\section{Study objectives}

The study was designed to address the following objectives:

1. Assess community awareness of HIV in children and young adults, including parent/guardians' knowledge and attitudes toward availability and benefits of HIV testing and treatment.

2. Assess the capacity of parents/caregivers to identify children and adolescents at risk of HIV infection and effectively refer them for testing and care, including ART, in a timely manner.

3. Work with partners to use research findings to develop and implement a small-scale intervention to increase the uptake of HIV testing and treatment among children and adolescents in selected study sites. 


\section{Hgrizons}

\section{Research questions}

The study was designed to explore the following research questions:

- What is the level of community awareness of HIV testing and treatment services for children and adolescents?

- What are the barriers preventing children from accessing HIV treatment?

- What strategies could be employed to increase the uptake of HIV treatment and care services for children and adolescents?

In this study report, we first present data exploring client barriers to pediatric HIV service delivery on the demand side, as expressed by community members through their responses to surveys and qualitative data collection exercises. We then present some more limited data investigating some of the supply side barriers to pediatric service delivery, as expressed through data collected at facilities from health service providers.

\section{Study Partners and Sites}

\section{Partners}

This study was a collaboration between Horizons/Population Council and four implementing partners:

a. Elizabeth Glaser Pediatric HIV/AIDS Foundation (EGPAF): EGPAF has been working in Kenya since 2000, providing PMTCT services at 236 facilities and pediatric ART at 30. For this study, EGPAF requested Horizons to focus on Eastern province, specifically Meru and Embu District Hospitals, where it has ongoing pediatric HIV activities.

b. Diocese of Nairobi Eastern Deanery AIDS Relief Program (EDARP): Founded in 1993, EDARP is part of the Catholic Church and implements community-based HIV and AIDS prevention and care programs in the Eastlands slums of Nairobi. A major component has been pediatric care and treatment, and EDARP has been treating HIV in children through its stand-alone HIV clinics or through integrated well-child facilities. For this study, EDARP requested Horizons to focus on Mathare and Soweto slums of Nairobi, where it is already implementing pediatric HIV activities.

c. Kenya Network of Women with AIDS (KENWA): Based in Nairobi and with health facilities in the slum areas, KENWA provides support to infected and disadvantaged women, and to children orphaned by AIDS. It provides hot meals to children, formula to prevent vertical transmission, treatment to PLHIV, and individual and group therapy. One KENWA health facility was included in this study.

d. Christian Health Association of Kenya (CHAK): CHAK is a consortium of Protestant churches of Kenya. It guides the operations of over 450 mission health facilities including 25 hospitals, 44 health centers, 310 dispensaries, and 55 church programs. CHAK also oversees eight schools of nursing, as well as two full universities. For this study, CHAK requested Horizons to focus on Nyanza province, specifically Rachuonyo district, where it is implementing pediatric HIV care through Kendu Bay Mission Hospital. 


\section{Study sites}

The study was conducted in three provinces in Kenya, namely Nairobi, Eastern, and Nyanza. These provinces were selected at the recommendation of the partner organizations, who would be implementing the interventions in these localities. Within each province, study sites were selected as follows:

a. Nairobi: Nairobi East (Soweto) and Nairobi North (Mathare and KENWA Pangani site).

b. Eastern province: Embu and Meru districts.

c. Nyanza province: Homa Bay and Rachuonyo districts.

One health facility per district was selected as the index site, for a total of six health facilities in the study plus a KENWA site. Since the study was conducted in three provinces in Kenya where study partners are already implementing pediatric HIV activities, and restricted to within a five kilometer catchment area of their health facilities, results are not intended to be seen as nationally representative; rather the intention is to focus attention on community awareness and utilization of services in areas where services are relatively well established, and to explore what can be done from outside the clinic setting to encourage the uptake of pediatric ARVs. 


\section{Hgrizons}

\section{Methods}

The study utilized both qualitative and quantitative methodologies. The qualitative methods used were focus group discussions (FGDs) and in-depth interviews (IDIs) with health care providers, district health management staff, community health workers, and members of PLHIV support groups. Unfortunately, civil unrest in Nairobi disrupted data collection and limited the research activities that could be conducted at the Nairobi sites.

Quantitative methods consisted of a community-based household survey of caregivers and a mini-survey of health workers. Additional research activities to explore infrastructure issues at each of the health facilities through a quantitative checklist were abandoned due to poor data quality and availability.

\section{Qualitative Methods}

\section{Focus group discussions with health providers}

At each of the seven sites (six district health facilities plus KENWA) one FGD was held among health providers in frequent contact with children at risk of HIV infection, including but not restricted to those who provided pediatric ART. Providers of differing types and levels of responsibility were represented, including counselors, clinical officers, and nurses. The total number of participants was 61.

\section{In-depth interviews with doctors and district health service management staff}

Across the health care facilities included in the study, IDIs were held with staff responsible for overseeing the district provision of pediatric ART, including clinic managers and doctors. A total of six IDIs were held. Participants were sought based on having responsibility for treating pediatric HIV or overseeing district service provision.

\section{FGDs with community health workers}

A total of six FGDs were held with community health workers affiliated with each facility. The total number of participants was 67.

\section{FGDs with parents who were members of AIDS-related support groups}

A total of 7 FGDs were conducted among openly HIV-positive parents over the age of 18 years who were members of PLHIV support groups managed by the four implementing partners. Discussions examined perceptions of pediatric ART among parents and community members, including barriers relating to decision-making, service satisfaction, futility/fear/fatalism, stigma, and side-effects. The total number of participants was 85 . Research staff aimed to make sure that the following groups were represented: 
- Male and female participants who were on ARV treatment themselves and those who were not.

- Participants whose (suspected) HIV-positive children aged under age 15 were receiving ART and those who were not.

- Parents of young children (aged under 5, who might be at risk of perinatal transmission) as well as those in their pre- and early teens [ages 8-15], who might be at risk of sexual transmission)

\section{Quantitative Methods}

\section{Household survey}

\section{Design}

The household survey was designed as a cross-sectional study, directed at an adult household respondent living in a household in which there was at least one resident child under the age of 15, including children who are the biological offspring of the household head and children who have been adopted or otherwise taken into the household (not just visiting). The study sample was calculated based on either of two indicators of community members' knowledge about pediatric HIV, namely the ability to identify three ways in which a child can be infected, or the ability to name three indications of a child who should be referred for HIV testing. The sample size was constructed on the conservative assumption that half the respondents knew the correct answer any of the above indicators, and the other half did not, comparing differences across provinces at 80 percent power and with 95 percent confidence. Factoring all these variables, calculations indicated a minimum required sample size of 384 respondents per province, or a total of 1,152 interviews for the survey.

The survey utilized a two-stage sample design. Within each province, two districts were selected. In order to reflect the study objective of assessing awareness and utilization of services, the study was deliberately restricted to households within a five kilometer radius of a facility with a pre-existing pediatric HIV service. Therefore the first stage of the sampling process was identification of the health facility. Once the study facility had been identified, the relevant enumeration area was mapped and boundaries identified. A total of 10 enumeration areas (EAs) in each district were thus identified. Within each EA, households within a five kilometer radius of the health facility were listed. A minimum of 60 and a maximum of 120 households per EA were listed. In this way, 6,859 dwellings in 60 EAs were listed. The second stage was the identification of eligible households and the selection of the sample. A total of 3,000 eligible dwellings (i.e., have at least one child under 15 years residing with an adult caregiver) were identified and formed the sampling frame for the study. From this sampling frame, 1,182 households were selected using systematic sampling procedures; houses that did not yield a respondent were replaced. In each eligible household, one male or female respondent was interviewed. The interviewers alternated malefemale respondents, generating a roughly equal gender split. At the conclusion of the fieldwork, research assistants had conducted interviews with a total 1,182 respondents. After dropping two respondents who did not provide complete information, the study sample was 1,180, which is the basis for this report.

\section{Data collection instruments}

The survey used multi-lingual face-to-face questionnaires. The questionnaire was designed with input from the study partners and the project advisory committee. Once the content was finalized, the questionnaire was translated into four languages: Kiswahili, Kiembu, Kimeru, and Dholuo. In addition, the English language questionnaire was available for respondents preferring this option. The data were collected by interviewers fluent in the local language. The questionnaires were pre-tested and revised 


\section{Hgrizons}

twice before data collection. They were also reviewed by the data entry team, in order to identify problems that could hamper data entry.

\section{Interviewer training}

Interviewers were trained over a five-day period in May 2007; 23 research assistants and three supervisors were recruited for this exercise. Most of the enumerators were university students or graduates who had conducted interview research before, and many had previously worked with Population Council. Training topics included the research objectives, interviewing skills, household listing, respondent selection, call-backs, quality control, obtaining consent, and ethics in research. The interviewer training included a field practicum, after which the questionnaire was revised, finalized, and printed. In each province, the research team comprised about eight interviewers and a supervisor. Supervisors received training covering household listing, household selection, field work management, and other aspects to enhance quality control.

\section{Fieldwork}

The sample size calculation called for interviewing 1,152 caregivers, split evenly between males and females. Interviews were structured to be evenly split between districts, i.e., about 192 per district. Data collection took place over a two week period between May and June 2007. Each interviewer conducted at least four interviews per day and each field team covered two villages per day with a few callbacks for the following day. After three unsuccessful efforts to locate a respondent, an alternate household was selected to be interviewed. There were less than 20 refusals in total across all sites in the study, resulting in a response rate of over 98 percent. Data collection in the Mathare slums was terminated prematurely, following a major civil unrest in the area that resulted in scores of deaths and extensive property damage.

Data processing and analysis

Once the data were collected, the supervisor reviewed the questionnaires and identified any problems needing correction. At the end of the day, the supervisor collated the questionnaires and entered them into a data collection registry. Each batch of questionnaires identified district, county, sub-county, and parish of origin. The consent forms were also collected, labeled, and stored in separate envelopes. The items were stored in a secure and locked box or room and prepared for shipping to Nairobi for data entry.

Data entry at Population Council offices began as soon as data collection was over, using EPI-DATA software version 3.02. The questionnaires were keyed twice to minimize data entry errors. Data were analyzed using SPSS v. 11 and STATA v 9.0 software.

\section{Mini-survey with health care personnel}

A mini-survey was developed for use among health workers in frequent contact with children at risk of HIV infection in order to review providers' experiences and contact with pediatric HIV testing and treatment services. Respondents included nurses, counselors, clinical officers, and doctors. The questionnaire was self-administered and was usually completed before the FGDs with the health workers. A total of 103 health care personnel participated in the study. However, six were dropped for belonging from cadres outside the scope of this study, leaving a sample size of 97. 


\section{Ethical Clearance and Approvals}

The questionnaires and consent forms were approved by the Population Council Institutional Review Board, the Kenyatta National Hospital Institutional Review Board, and the National Council for Science and Technology. In each district, the study also sought the approval of district officials, community gatekeepers, and others as appropriate. Each respondent interviewed in the study provided written informed consent prior to commencement of the interview. The questionnaires and consent forms were stored separately in order to ensure no identifying information could be linked.

\section{Study Limitations}

\section{HIV status not requested}

Although this was a study about pediatric HIV, the household survey did not inquire about the HIV status of anyone, including either the respondent or their children, due to ethical concerns. Therefore the findings regarding how caregivers would respond were they confronted with pediatric HIV in their household are somewhat speculative. However, the study conducted FGDs with members of PLHIV support groups, and these may provide a more experience-based perspective.

\section{Children's participation}

Another limitation was the exclusion of children as respondents. Children themselves are the experts on being children. The inclusion of children's own views reflecting upon aspects of their treatment and care would be an extremely valuable element adding new and important perspectives on pediatric HIV to this study. However, due to logistical, timing, and ethical constraints, this study did not directly explore the views of young people themselves.

\section{Focus on children living with adult caregivers in the community}

This study was designed specifically to focus on the circumstances of children who are living in the care of adults within the community. Children who are living in institutions (e.g., orphanages, children's villages, informal children's homes), children who are living on the streets, and children who are living in child-headed households are all excluded from this study. It is recognized that understanding the diverse needs of all these groups of children is beyond the scope of this study; however, it is hoped that findings from this study will inform future work among other groups of children. 


\section{Hgrizons}

\section{Results}

Since the report draws from multiple data sources detailed above, results will be presented thematically, integrating quantitative and qualitative sources. Analysis will mainly be presented at the provincial level unless there are sharp differences by district.

Unless otherwise indicated, statistical analysis tested for significance using Pearson's chi-square test. Throughout this report, differences statistically significant at the 0.05 level are indicated by *; differences statistically significant at the 0.01 level are indicated by $* *$.

\section{Community Sociodemographic Profile}

The household survey reached 1,182 respondents, approximately evenly divided between males and females and across the three sites (see Table 1). About 71 percent of respondents resided in urban areas, 52 percent had reached primary school, and 82 percent were married. Half were peasant farmers, laborers, or small traders. Survey data indicate that 35 percent of participant households had electricity, 31 percent had piped water into their dwelling, 81 percent had a radio, and 37 percent had a TV. These results are roughly comparable to national socioeconomic data from the 2003 KDHS indicating that 50 percent of urban households had electricity, 19 percent had piped water into their dwelling, 81 percent had a radio, and 41 percent had a TV (Central Bureau of Statistics [Kenya], Ministry of Health [Kenya] et al. 2004). 
Table 1 Sociodemographic characteristics of household survey respondents

\begin{tabular}{|c|c|}
\hline Variable & $\begin{array}{c}(n=1,180) \\
\%\end{array}$ \\
\hline $\begin{array}{l}\text { Sex } \\
\text { Male : Female }\end{array}$ & $48: 52$ \\
\hline $\begin{array}{l}\text { Age } \\
\text { Mean age } \\
\text { Age range }\end{array}$ & $\begin{array}{c}35 \text { years } \\
18-84 \text { years }\end{array}$ \\
\hline $\begin{array}{l}\text { Province } \\
\text { Nairobi }(n=375) \\
\text { Eastern }(n=401) \\
\text { Nyanza }(n=404)\end{array}$ & $\begin{array}{l}31 \\
34 \\
35\end{array}$ \\
\hline $\begin{array}{l}\text { Level of education } \\
\text { None } \\
\text { Primary } \\
\text { Secondary } \\
\text { College/university }\end{array}$ & $\begin{array}{r}5 \\
52 \\
32 \\
10\end{array}$ \\
\hline $\begin{array}{l}\text { Marital status } \\
\text { Married } \\
\text { Divorced/separated } \\
\text { Widowed }\end{array}$ & $\begin{array}{c}82 \\
6 \\
7\end{array}$ \\
\hline $\begin{array}{l}\text { Assets } \\
\text { Have electricity } \\
\text { Have radio } \\
\text { Have TV }\end{array}$ & $\begin{array}{l}35 \\
81 \\
37\end{array}$ \\
\hline $\begin{array}{l}\text { Source of water } \\
\text { Piped to own home } \\
\text { Piped to communal tap } \\
\text { Use well or bore hole } \\
\text { Buy } \\
\text { From river, lake, pond, etc }\end{array}$ & $\begin{array}{r}31 \\
22 \\
8 \\
19 \\
20\end{array}$ \\
\hline $\begin{array}{l}\text { Occupation } \\
\text { Peasant/small scale trader } \\
\text { Unskilled (e.g., laborer) } \\
\text { Skilled/technical (e.g., clerk, welder) } \\
\text { Housewife } \\
\text { Professional (e.g., teacher) }\end{array}$ & $\begin{array}{r}34 \\
21 \\
15 \\
12 \\
8\end{array}$ \\
\hline
\end{tabular}

Note: Percentages may not add up to 100 due to rounding, omission of smaller subgroups, and/or multiple responses

\section{Household composition}

Across the three sites, there was a mean of 4.8 people living in each household, including the respondent; comprising a mean of 2.6 adults and 2.3 children. Households in Nyanza had the largest number of members (mean 5.8), followed by those in Eastern province (mean 4.4), and Nairobi province (mean 4.3). Across the three sites, 67 percent of households had a member who was under five years of age (58 percent of households in Eastern, 67 percent in Nyanza, and 78 percent in Nairobi). 


\section{Hgrizons}

Across the three sites, 23 percent of households included a resident child who was not the biological offspring of the survey respondent. As shown in Table 2, a total of 2,844 children under age 15 were living in the households covered by the household survey, evenly split between girls and boys. Most (83 percent) were biological children of the respondents, ranging from 92 percent of those in Nairobi to 76 percent of those in Nyanza. Of the remaining 484 children currently residing in the household who were not the biological children of the household head, 94 percent had been adopted and 6 percent were visiting. Most ( 80 percent) had been living in the household for more than a year. About 64 percent had no biological parent living there, 26 percent had only a mother living there, 5 percent had only a father living there, and 6 percent had both parents living there.

Table 2 also shows that for those children whose biological parents were not living in the household, 34 percent still had both parents alive but living elsewhere, 24 percent knew that both parents were dead, 15 percent knew that the father was dead, and 9 percent knew that the mother was dead. In about 19 percent of the cases, the status of the parents was unknown. 
Table 2 Characteristics of children (under age 15) living in surveyed households

\begin{tabular}{|c|c|c|c|c|c|c|c|c|}
\hline \multirow[b]{2}{*}{ Characteristics } & \multicolumn{4}{|c|}{ All children } & \multicolumn{4}{|c|}{$\begin{array}{l}\text { Children who are not the biological } \\
\text { offspring of survey respondent }\end{array}$} \\
\hline & $\begin{array}{c}\text { Nairobi } \\
(n=775) \\
\%\end{array}$ & $\begin{array}{c}\text { Eastern } \\
(\mathrm{n}=747) \\
\%\end{array}$ & $\begin{array}{c}\text { Nyanza } \\
(\mathrm{n}=1,322) \\
\%\end{array}$ & $\begin{array}{c}\text { All } \\
(n=2,844) \\
\%\end{array}$ & $\begin{array}{c}\text { Nairobi } \\
(n=64) \\
\%\end{array}$ & $\begin{array}{c}\text { Eastern } \\
(\mathrm{n}=105) \\
\%\end{array}$ & $\begin{array}{c}\text { Nyanza } \\
(\mathrm{n}=315) \\
\%\end{array}$ & $\begin{array}{c}\text { All } \\
(n=484) \\
\%\end{array}$ \\
\hline $\begin{array}{l}\text { Sex of child } \\
\text { Male } \\
\text { Female }\end{array}$ & $\begin{array}{l}53 \\
47\end{array}$ & $\begin{array}{l}53 \\
48\end{array}$ & $\begin{array}{l}51 \\
49\end{array}$ & $\begin{array}{l}52 \\
48\end{array}$ & $\begin{array}{l}53 \\
47\end{array}$ & $\begin{array}{l}57 \\
43\end{array}$ & $\begin{array}{l}49 \\
51\end{array}$ & $\begin{array}{l}52 \\
49\end{array}$ \\
\hline $\begin{array}{l}\text { Relationship to } \\
\text { caregiver } \\
\text { Own child } \\
\text { Stepchild } \\
\text { Grandchild } \\
\text { Sibling } \\
\text { Other relative } \\
\text { Unrelated }\end{array}$ & $\begin{array}{c}92^{*} \\
1 \\
4 \\
1 \\
2 \\
1\end{array}$ & $\begin{array}{r}86 \\
1 \\
8 \\
1 \\
3 \\
1\end{array}$ & $\begin{array}{c}76 \\
2 \\
12^{*} \\
1 \\
8 \\
1\end{array}$ & $\begin{array}{r}83 \\
2 \\
9 \\
1 \\
5 \\
1\end{array}$ & $\begin{array}{r}0 \\
14 \\
45 \\
16 \\
20 \\
5\end{array}$ & $\begin{array}{r}0 \\
10 \\
57 \\
10 \\
19 \\
5\end{array}$ & $\begin{array}{r}0 \\
9 \\
51 \\
5 \\
33 \\
2\end{array}$ & $\begin{array}{r}0 \\
10 \\
52 \\
7 \\
28 \\
3\end{array}$ \\
\hline $\begin{array}{l}\text { Is child adopted or } \\
\text { visiting } \\
\text { Adopted } \\
\text { Visiting }\end{array}$ & $\mathrm{n} / \mathrm{a}$ & $\mathrm{n} / \mathrm{a}$ & $\mathrm{n} / \mathrm{a}$ & $\mathrm{n} / \mathrm{a}$ & $\begin{array}{c}100^{*} \\
0\end{array}$ & $\begin{array}{l}90 \\
11\end{array}$ & $\begin{array}{r}94 \\
6\end{array}$ & $\begin{array}{r}94 \\
6\end{array}$ \\
\hline $\begin{array}{l}\text { Duration of living } \\
\text { with the child } \\
1 \text { year or less } \\
\text { more than } 1 \text { year }\end{array}$ & $\mathrm{n} / \mathrm{a}$ & $\mathrm{n} / \mathrm{a}$ & $\mathrm{n} / \mathrm{a}$ & $\mathrm{n} / \mathrm{a}$ & $\begin{array}{l}16 \\
84\end{array}$ & $\begin{array}{l}22 \\
78\end{array}$ & $\begin{array}{l}21 \\
79\end{array}$ & $\begin{array}{l}20 \\
80\end{array}$ \\
\hline $\begin{array}{l}\text { Parents living in the } \\
\text { household } \\
\text { Mother only } \\
\text { Father only } \\
\text { Both parents } \\
\text { None }\end{array}$ & $\mathrm{n} / \mathrm{a}$ & $\mathrm{n} / \mathrm{a}$ & $\mathrm{n} / \mathrm{a}$ & $\mathrm{n} / \mathrm{a}$ & $\begin{array}{c}39 \\
2 \\
13^{*} \\
47\end{array}$ & $\begin{array}{r}37 \\
1 \\
2 \\
60\end{array}$ & $\begin{array}{c}20^{*} \\
6 \\
5 \\
69^{*}\end{array}$ & $\begin{array}{r}26 \\
5 \\
6 \\
64\end{array}$ \\
\hline $\begin{array}{l}\text { Parents living status } \\
\text { Both parents alive } \\
\text { Father only dead } \\
\text { Mother only dead } \\
\text { Both parents dead } \\
\text { Status unknown }\end{array}$ & $\mathrm{n} / \mathrm{a}$ & $\mathrm{n} / \mathrm{a}$ & $\mathrm{n} / \mathrm{a}$ & $\mathrm{n} / \mathrm{a}$ & $\begin{array}{r}41 \\
19 \\
6 \\
14 \\
20\end{array}$ & $\begin{array}{r}40 \\
11 \\
6 \\
7 \\
36^{*}\end{array}$ & $\begin{array}{l}30 \\
16 \\
11 \\
31^{*} \\
12 \\
\end{array}$ & $\begin{array}{r}34 \\
15 \\
9 \\
24 \\
19 \\
\end{array}$ \\
\hline
\end{tabular}

${ }^{*} \mathrm{p} \leq 0.05$

\section{Health-seeking Behaviors}

\section{Uptake of clinic services}

In the household survey, respondents were asked where they seek care if their child under age 15 is sick enough to require outside consultation. Nearly all (98 percent) said they seek care at a health care facility. Almost all respondents (94 percent) had sought care the last time a child was unwell, and of these, 75 percent had visited a public health facility and 23 percent a private clinic. The main reason given for 


\section{Hgrizons}

preferring the facility they chose was good quality of care (51 percent), affordability (48 percent), proximity to home (36 percent), quick service (14 percent), and "usually goes there" (11 percent).

Figure 1 illustrates the percentage of survey respondents who had ever sought care at the catchment facility associated with their study area. Rates were higher in Eastern and Nyanza facilities where facilities are public, larger, and better known: attendance at the established public facilities of Embu, Meru, and Homa Bay District Hospitals was 67 percent, 71 percent, and 67 percent respectively. Meanwhile at the smaller, private sector facilities in Nairobi and Rachuonyo, attendance was 15 percent in Soweto, 9 percent in Mathare, and 13 percent in Rachuonyo.

\section{Figure 1 Percent of respondents who have sought care in catchment area for child under age 15 by province, household survey}

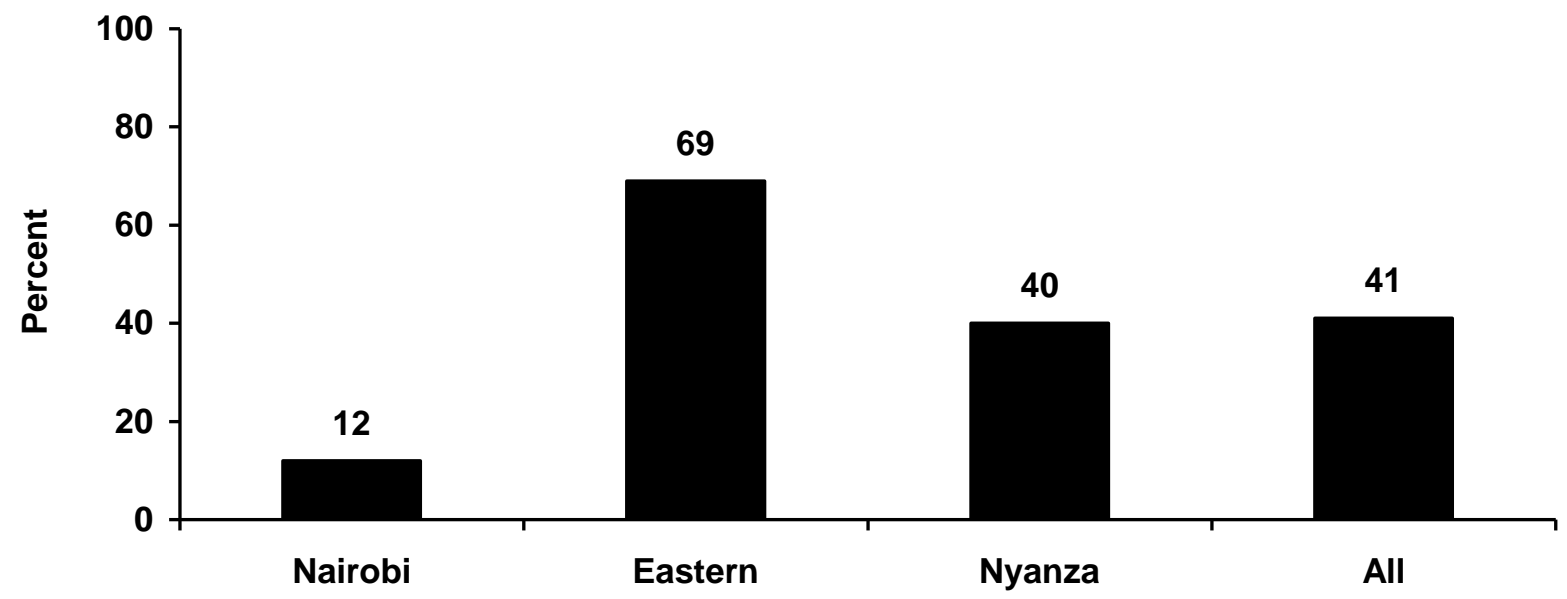

During discussions with PLHIV support group members, many noted that some people may not seek HIV-related care at their nearest facility, in order to avoid stigma. They may be willing to face higher transport costs to reach a distant facility where they would not be recognized.

Many people, who come from around here, don't make use of this facility. The group you see here is not from the local community. Even the children brought here are not from very near. The services here are good but fear of stigma still puts them off. Some go for similar services as far as Eldoret where no one knows them.

PLHIV support group member, Nyanza

Another barrier was lack of awareness of the facility, especially in the Nairobi sub-sample. About 23 percent of caregivers said they had not attended the facility because they did not know of it, compared to zero percent of the respondents in Eastern and Nyanza provinces, largely because the hospitals in the latter facilities are known district and provincial hospitals, or are the only major hospital in the case of Kendu Bay Mission Hospital. The Nairobi health facilities, on the other hand, are located in crowded and densely populated slum areas, where there are numerous other privately-owned facilities, both licensed and unlicensed. This suggests that appropriate signage and branding of health facilities offering quality pediatric services is particularly important so that the public can be informed where to take their children. 


\section{Utilization of traditional and religious healers}

In the household survey, less than 1 percent of community survey respondents reported that they had sought care from a traditional healer or similar source the last time their child (aged under 15) was unwell. However, FGDs indicated that for some caregivers (especially in Eastern and Nyanza provinces), traditional and religious healers are still the first from whom they seek health care. Discussions revealed that people seek care first at traditional healers because their services are affordable, accessible, and nonstigmatizing.

There are some people who... first, they try taking their children to traditional doctors. When they are completely unable that is when maybe they take to hospital. But at first you will find that they will go to traditional doctors. You can get them [traditional healers] faster. Also you know the job is done in the bush so there is nobody who will associate you with HIV. You won't be associated with it [HIV], and...it is cheap.... It is very cheap. Because even though ARVs are free in the general hospital, you will use transport, then you go and stay there the whole day.

PLHIV support group member, Eastern

FGDs also revealed that cultural beliefs about the cause of AIDS, such as witchcraft and failure to follow traditions, often prompted caregivers to seek alternative healing solutions. Especially in Nyanza, community members talked about traditional beliefs in "chira," explained as a traditional disease in which one grows thin to which many signs and symptoms of pediatric HIV could be attributed. Chira was reported to be associated with the non-fulfillment of traditional Luo sexual customs, including sexual cleansing following childbirth and agricultural sexual traditions associated with harvesting and planting seasons.

The belief in most communities here is that the traditional healers have preventive or corrective measures to HIV [and] chira. Chira comes about when traditions are breached, for example a couple did not have sex before start of plowing or planting season. The traditional healer is believed to revert the condition back to normal should a sickness set in because of that misconduct. The symptoms resemble that of HIV and that is the reason people don't have a clear-cut difference between chira and HIV-related symptoms.

PLHIV support group member, Nyanza

During FGDs, health care providers concurred that caregivers bring children in for testing and treatment only when all other options have failed and when the child's health is acutely threatened, so treatment options are limited and prognosis is often poor. When such children die despite being treated at the clinic, this may be interpreted as an inability of modern medicine to save them, thus perpetuating community distrust of clinic services and further discouraging the use of modern clinics over traditional healers.

...due to ignorance or carelessness, some parents/caregivers wait until the child is in acute attack of OIs [opportunistic infections] before they think of taking the child for medication. This becomes a challenge because the parent becomes desperate at the time the child is very sick. Parents need to be alert on the child's health status most of the time.

Community health worker, Nyanza 


\section{Hgrizons}

Those of us who have been educated on HIV care and treatment know that HIV does not get treated using traditional herbs. We straight away go for tests once you detect HIV-related signs and you are put on modern medicine if your condition demands ARVs. The same is true for children.

PLHIV support group member, Nyanza

Most children brought to us come here when they are very sick... there is nothing much we can do about them.

Pharmaceutical technician, Nairobi

However, some community members reported that reliance on traditional healing is becoming less popular with increasing frustration with traditional remedies and increasing awareness of HIV and modern health care. Community members provided illustrations of what they saw as manipulative behavior by traditional healers to reduce reliance on modern medicine and promote the role of traditional medicine. For example, when asked, "What interpretations do the religious healers give in the event that no healing happens?" a PLHIV support member replied:

They say you have less faith. It is your hard heart that has tied the child in the prevailing sickness. So the parent/caregiver bears the blame of the persistent illness.... He [the witch doctor] makes sure the cost of this next step is so exorbitant that you may not come back to him. For example he knows you cannot afford a goat so he will tell you to bring a cow..... So when your child dies, you will blame it on your inability to produce the cow for the proposed more specialized treatment that would have saved the life of the child.

PLHIV support group members, Nyanza

Health workers gave examples of some of the strategies they use to counter traditional beliefs and encourage greater reliance on modern medicine, in the community and in schools. However, many requested guidance as to how to respond to clients seeking both traditional and clinic care. As participants of the qualitative research talked more and more about traditional healing, it became apparent that interactions between traditional healing and the services provided at the clinic need to be accounted for. The division between traditional and medical healing should not be viewed as a dichotomy-rather, there are multiple avenues to seek the different types of care that may be followed concurrently for both adults and children, which clinic service providers need to be aware of especially in adherence counseling. For example, once diagnosed as HIV-positive through a medical test and prescribed ART at a clinic, a client may then proceed to seeking traditional remedies to use alongside the ART. Some respondents acknowledged that following the traditional or religious healing procedures may prevent HIV testing or require the client to abandon their ART in order to demonstrate their faith in the religious healing, as expressed by a health worker in Nyanza: "Those who believe, sit and wait" (nurse, outpatient department). Health workers in Eastern province explained that they encounter clients who even ask to be discharged from care in order to go to a traditional healer when they see no visible improvement from medical treatment.

You counsel a client during adherence counseling but when they go home on the drugs and... a relative may say this is not the disease, let us try herbs.

Health worker (MCH FP), Nyanza

You will find that a child is taken for prayers, and they believe that the child will recover when taken to those prayers. They say they will pray for him/her and those drugs from hospital staff, 
he/she will stop taking them. And they believe that he or she will recover but those are just lies. That child will still have the disease, even though they will pray for him/her.

PLHIV support group member, Eastern

I tell them prayers are good, but we also take drugs because God is there. I got sick and drugs are available. Those who did not get treatment are not there.

Community health workers, Nairobi

Therefore in summary, utilization of alternative care providers such as traditional and faith healers affects caregivers' decisions about seeking clinical care, especially in Nyanza and Eastern provinces.

\section{Quality of Care}

\section{Client perceptions of quality of care}

Household survey respondents who had patronized study partners' facilities for pediatric care in the past 12 months were asked about their perceptions of the quality of care that they had received for their child. The data show that across all sites, 18 percent of respondents who had visited the facilities were displeased with the service they had been offered. Satisfaction levels varied by site: 10 percent were dissatisfied at Meru, 13 percent at both Mathare and Homa Bay facilities, 17 percent at Soweto, 19 percent at Embu, and up to 30 percent (of 27 respondents) at the Rachuonyo facility.

Table 3 shows some of the reasons respondents cited for not having attended the catchment facility recently, which focus on discouraging experiences during a previous visit. Lack of drugs was reported as a consistent problem at all sites, but especially in Eastern province. Other complaints that had put respondents off from further visits were long waiting times and unfriendly or incompetent providers. Cost was of particular concern in Nyanza.

Table 3 Reasons for displeasure with service the last time household survey respondent attended nearby health facility ${ }^{+}$

\begin{tabular}{lcccc}
\hline & $\begin{array}{c}\text { Nairobi } \\
\mathbf{n = 7}\end{array}$ & $\begin{array}{c}\text { Eastern } \\
\mathbf{n = 5 5} \\
\%\end{array}$ & $\begin{array}{c}\text { Nyanza } \\
\mathbf{n = 2 6} \\
\%\end{array}$ & $\begin{array}{c}\text { All } \\
\mathbf{n = 8 8} \\
\%\end{array}$ \\
\hline Lack of drugs & $3 / 7$ & 73 & 27 & 57 \\
Long waiting time & $2 / 7$ & 49 & 35 & 43 \\
Unfriendly providers & $3 / 7$ & 27 & 19 & 26 \\
Cost & $1 / 7$ & 9 & 50 & 22 \\
Provider incompetence & $2 / 7$ & 13 & 19 & 16 \\
Poor hours of operation & $2 / 7$ & 2 & 4 & 5 \\
Facility too far & 0 & 2 & 4 & 2 \\
\hline
\end{tabular}

${ }^{+}$Multiple responses allowed 


\section{Hgrizons}

Client dissatisfaction with services was further explored during FGDs: one major source of frustration was that each appointment may be very time-consuming due to long waits, representing not just a delay but also an increase in the opportunity cost of seeking services. Hospital staff acknowledged these frustrations and recognized the limitations of their own services. Some of the causes they cited for the delays included limited lab facilities, problems with equipment, and shortage of supplies. Since PCR tests have to be sent away for processing, results are delayed, leading to frustration and resentment. As a health worker in Eastern province commented:

We have experiences where a mother comes after one month and tell us that the results are not yet back, and when we go further to the lab, to the people concerned, they tell us that it's true, the results are not yet back. We try to encourage them that the results will come out after six weeks.

Clinical officer, MCH, Eastern

Patients also expressed frustrations about lack of supplies.

Sometimes you're told to go and buy gloves and syringes, and there [are] times I cannot afford to buy. The doctors complain that the equipments have finished.

PLHIV support group member, Eastern

\section{Health provider attitudes}

In order to explore whether negative health provider attitudes were a barrier to accessing care (in the local area, not just at the study site), household respondents were asked to respond to a series of statements characterizing their views of health workers (see Table 4). Results varied: a majority of respondents felt that health workers blame parents for the illnesses of their children, and substantial percentages of respondents reported feeling that providers do not listen to patients, do not understand their needs, and do not allow them to ask questions. Respondents in Nyanza appeared the most disappointed with health workers in their area. More encouragingly, few respondents expressed fears that providers would divulge their HIV status to other people, and they seemed relatively confident that they would not be stigmatized by their health workers due to HIV. 
Table 4 Respondent views on health workers, household survey

\begin{tabular}{|c|c|c|c|c|}
\hline & $\begin{array}{c}\text { Nairobi } \\
n=375 \\
\%\end{array}$ & $\begin{array}{c}\text { Eastern } \\
n=401 \\
\%\end{array}$ & $\begin{array}{c}\text { Nyanza } \\
n=404 \\
\%\end{array}$ & $\begin{array}{c}\text { All } \\
n=1180 \\
\%\end{array}$ \\
\hline \multicolumn{5}{|c|}{$\begin{array}{l}\text { Agree that HWs blame caretakers for the } \\
\text { illness of their children }\end{array}$} \\
\hline Male & 45 & 40 & 78 & $55^{*}$ \\
\hline Female & 50 & 45 & 83 & $59^{*}$ \\
\hline All & 48 & 42 & 81 & 57 \\
\hline \multicolumn{5}{|c|}{ Agree that HWs do not listen to patients } \\
\hline Male & 40 & 45 & 66 & $51^{*}$ \\
\hline Female & 30 & 37 & 606 & $42^{*}$ \\
\hline All & 34 & 40 & 63 & 46 \\
\hline \multicolumn{5}{|c|}{$\begin{array}{l}\text { Disagree that HWs allow patients to ask } \\
\text { questions }\end{array}$} \\
\hline Male & 31 & 34 & 52 & 40 \\
\hline Female & 26 & 39 & 44 & 36 \\
\hline All & 28 & 37 & 48 & 38 \\
\hline \multicolumn{5}{|c|}{ Disagree that HWs treat patients with respect } \\
\hline Male & 23 & 33 & 54 & 38 \\
\hline Female & 26 & 28 & 49 & 34 \\
\hline All & 25 & 30 & 52 & 36 \\
\hline \multicolumn{5}{|c|}{$\begin{array}{l}\text { Agree that HWs do not understand the needs } \\
\text { of their patients }\end{array}$} \\
\hline Male & 36 & 42 & 56 & 46 \\
\hline Female & 34 & 36 & 53 & 41 \\
\hline All & 35 & 39 & 55 & 43 \\
\hline \multicolumn{5}{|c|}{$\begin{array}{l}\text { Agree that HWs would tell others if the } \\
\text { patient were HIV+ }\end{array}$} \\
\hline Male & $14^{*}$ & 14 & 26 & 18 \\
\hline Female & $19^{*}$ & 11 & 27 & 19 \\
\hline All & 17 & 13 & 26 & 19 \\
\hline \multicolumn{5}{|c|}{$\begin{array}{l}\text { Agree that HWs would stigmatize people who } \\
\text { are infected with HIV }\end{array}$} \\
\hline Male & $14^{*}$ & 19 & 27 & $20^{*}$ \\
\hline Female & $13^{*}$ & 11 & 21 & $15^{*}$ \\
\hline All & 13 & 15 & 24 & 17 \\
\hline
\end{tabular}

*Differences by sex statistically significant at $p \leq 0.05$. Significance may be due to "can't decide," not shown

To provide an overall assessment of health care workers, a composite score was developed from the items listed in Table 4. Each response reflecting dissatisfaction with provider behavior was awarded one point, so total scores could range from zero (reflecting the most positive opinion of providers) up to 7 (reflecting the most negative opinion of providers). As illustrated by Figure 3, scores reflected significantly more dissatisfaction with health care providers in Nyanza (mean score 3.4) than in Nairobi and Eastern provinces (mean scores 2.1 and 2.2, respectively). Thus concerns about health workers in Nyanza may be a particular barrier to care for pediatric patients. 
Figure 2 Dissatisfaction with health workers by region, household survey

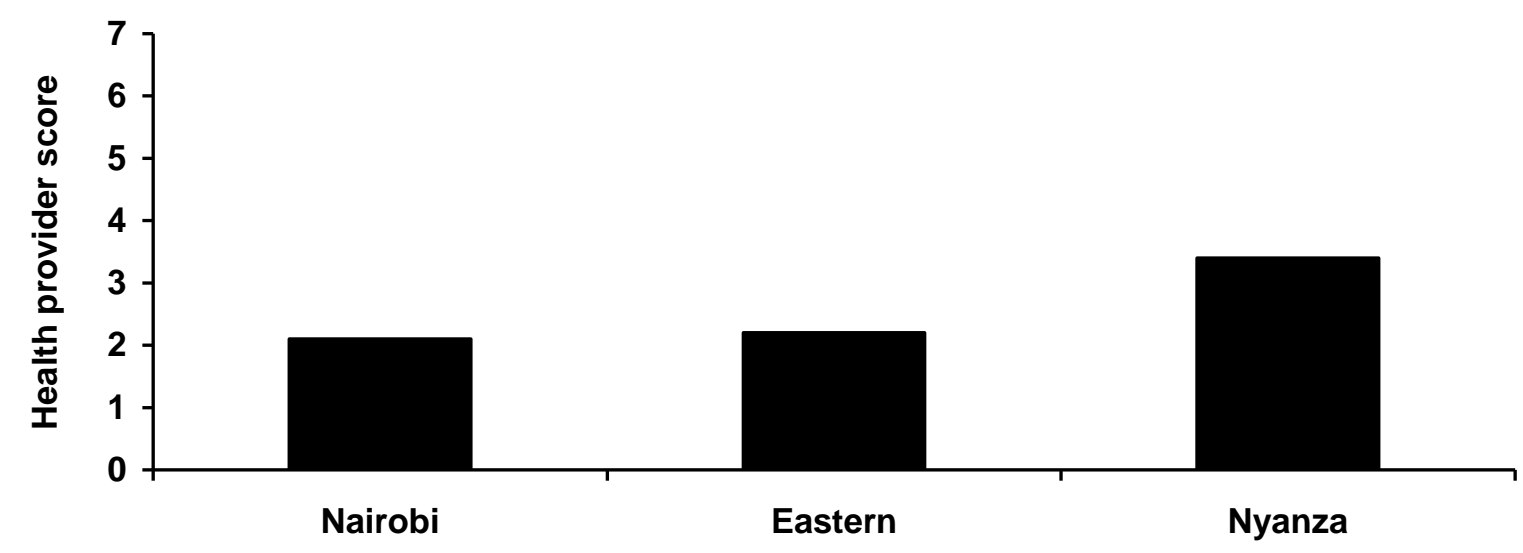

The effects of the provider attitudes were made disturbingly clear by survey respondents: 20 percent of male and female survey respondents (with no significant differences by sex) said that they had failed to take their child for care in the 12 months preceding the survey as a result of unfriendly providers.

Respondents most likely to avoid seeking care because of provider attitudes were in Rachuonyo (32 percent), followed by Homa Bay (21 percent), Meru (18 percent), Soweto and Mathare (20 percent each), and Embu (15 percent).

These findings were supported by the qualitative research. Support group members and community health workers reported dissatisfaction with clinic staff who had been harsh or even rude to them, although others commented that rudeness had recently decreased at Homa Bay. Another frequent complaint about clinic staff was that they favored their friends with quick service before other people who were waiting.

It's not uncommon to hear a patient pondering, "That nurse has really annoyed me. Why all that animosity against me when I merely went there for medical attention?" This discourages parents/caretakers from accessing care including HIV-related services for their children. The nurses were trained to administer injections but not on how to talk to people. Please re-train the nurses on communication to improve access to health care for adults and children, including HIV services.

Community health worker, Nyanza

A provider will withdraw his friend or relative from the queue and treat him while other people continue to wait. ...even when a patient's condition worsens, the provider still keeps him in the queue and does not care whether you are dying or alive. They don't have ways of detecting which patient cannot be put to wait. They can call a healthy looking patient in and spend time with him while another patient whose condition is worse continues to wait.

PLHIV support group member, Nyanza

Client comments about the quality of care were commonly linked to cost: positive discussion focused on elements of care that are provided free of charge, and dissatisfaction was more commonly expressed with service elements for which fees are charged (e.g., prescriptions for OI [opportunistic infection] drugs). Confidentiality concerns remain a major concern among clients of HIV-related services. 
We are happy because we have been able to get free HIV treatment and this has sustained our lives and lives of our children. We would be dead if free treatment was not there; our children would be dead too.

PLHIV support group member, Nyanza

Quality of health care is good but there is fear of local workers disclosing secrets of patients to the entire community. Some people who come from around Gendia here cover their heads with leso [headscarf], if women, to disguise their identity if they choose to come for services here for themselves or for their children because they fear stigma from community members or by the service providers.

PLHIV support group member, Nyanza

\section{Client-provider communication about HIV}

Respondents of the household survey discussed information shared during client-provider interactions associated with antenatal care (ANC) and the well-baby clinic. ANC represents a window of opportunity for providers to discuss PMTCT and pediatric HIV testing, especially since coverage of ANC was high among this population: 95 percent of respondents with a child under age 5 reported that they or the child's mother had received ANC during the last pregnancy. Among women who had received ANC during the last five years, including male caregivers reporting on their partner, 74 percent across the three provinces reported that they had been told about PMTCT during pregnancy. Meanwhile, among male respondents, 61 percent of men reported that their partner had been told about PMTCT, and 26 percent of men said they did not know whether their partners had been told this information, suggesting a need for greater partner communication about this matter.

Over the previous four years, the government has provided PCR testing in central referral laboratories, in order to enable early infant diagnosis. Children can be tested for HIV as early as six weeks of age, compared to previously when antibody testing necessitated waiting until a child was 18 months of age. In order to assess the extent to which survey respondents had acquired this new information, all those who attended ANC were asked whether they were aware that children could be tested for HIV as early as six weeks. The results show that about half were aware, with women more likely to know than men (57 percent vs. 47 percent, $\mathrm{p}=0.006$ ), with small differences by province (respondents in Nyanza were the most likely to be aware, at 59 percent, followed by those in Nairobi and Eastern provinces at 53 percent each). 
Table 5 Communication about pediatric HIV during various service delivery opportunities, among respondents with a child aged under 5 years, household survey

\begin{tabular}{|c|c|c|c|c|}
\hline & $\begin{array}{l}\text { Nairobi } \\
n=293\end{array}$ & $\begin{array}{l}\text { Eastern } \\
\mathrm{n}=234\end{array}$ & $\begin{array}{l}\text { Nyanza } \\
\mathrm{n}=269\end{array}$ & $\begin{array}{c}\text { All } \\
\mathrm{n}=796\end{array}$ \\
\hline \multicolumn{5}{|c|}{ Child's mother received ANC last pregnancy (\%) } \\
\hline Male $^{+}$ & 92 & 96 & 94 & 94 \\
\hline Female & 98 & 97 & 93 & 96 \\
\hline All & 95 & 97 & 93 & 95 \\
\hline \multicolumn{5}{|c|}{$\begin{array}{l}\text { Child's mother told about PMTCT among attending } \\
\text { ANC (\%) }\end{array}$} \\
\hline Male & $65^{\star}$ & $63^{*}$ & $56^{*}$ & $61^{*}$ \\
\hline Female & $79^{*}$ & $77^{\star}$ & $65^{\star}$ & $74^{*}$ \\
\hline All & 73 & 71 & 60 & 68 \\
\hline \multicolumn{5}{|c|}{$\begin{array}{l}\text { Aware that children can be tested as early as } 6 \\
\text { weeks among those attended ANC (\%) }\end{array}$} \\
\hline Male & 54 & $38^{*}$ & $47^{*}$ & $47^{\star}$ \\
\hline Female & 51 & $58^{*}$ & $63^{*}$ & $57^{*}$ \\
\hline All & 53 & 48 & 54 & 52 \\
\hline \multicolumn{5}{|c|}{ Mean \# ANC visits of attended by child's mother } \\
\hline Male & 5 & 5 & 5 & 5 \\
\hline Female & 6 & 5 & 4 & 4 \\
\hline All & 5 & 5 & 4 & 5 \\
\hline \multicolumn{5}{|c|}{$\%$ of deliveries taking place in a health facility } \\
\hline Male & 68 & 98 & 43 & 68 \\
\hline Female & 59 & 92 & 49 & 66 \\
\hline All & 63 & 95 & 47 & 67 \\
\hline \multicolumn{5}{|c|}{ Child taken to well-baby clinic (\%) } \\
\hline Male & 81 & 95 & 85 & 86 \\
\hline Female & 81 & 98 & 97 & 91 \\
\hline All & 81 & 96 & 90 & 89 \\
\hline \multicolumn{5}{|c|}{$\begin{array}{l}\text { Child's mother told about child testing among those } \\
\text { attended well-baby clinic (\%) }\end{array}$} \\
\hline Male & $41^{*}$ & $44^{*}$ & $52^{*}$ & $46^{*}$ \\
\hline Female & $41^{*}$ & $50^{*}$ & $61^{*}$ & $50^{*}$ \\
\hline All & 41 & 48 & 56 & 48 \\
\hline
\end{tabular}

${ }^{+}$Male respondents were asked about the ANC utilization by the mother of the index child. ${ }^{*} \mathrm{p} \leq 0.05$

Regardless of antenatal clinic attendance, respondents with a child under age five years were asked whether their youngest child had been taken to the well-baby clinic. The results show that 89 percent of respondents answered affirmatively, including 91 percent of female and 86 percent of male caregivers.

Among those who said that their child was taken to the well-baby clinic $(n=705)$, around 48 percent of respondents said that they had been informed about pediatric HIV testing, including 46 percent of males and 50 percent of females. Most likely to receive this advice were survey respondents in the Nyanza facilities ( 56 percent), followed by those in Eastern (48 percent), and Nairobi (41 percent; see Table 5). 
With the new NASCOP directive about pediatric HIV testing, it is anticipated that these figures will increase as more well-baby clinics inform caregivers about testing children.

All respondents were asked whether a health worker had ever advised them to have their children under the age of 15 years tested for HIV. The results show that only 11 percent of survey respondents (10 percent of males, 12 percent of females) had ever received such advice. Most likely to report such advice were those from Nyanza (16 percent among all, no difference between males and females), followed by Nairobi (13 percent among all, 16 percent among women and 9 percent among men), and by far the least were respondents in Eastern (4 percent among all, no difference between males and females).

\section{Practical Barriers to Care: Cost, Distance, and Time}

The study team investigated the affordability of care by asking household survey respondents who had used the pediatric services of the catchment facility during the preceding 12 months $(n=485$ respondents) about the cost of transport, consultation fees, and drugs associated with their visit. The results, presented in Table 6, show that the mean cost of transport to the catchment facility was KSh $22^{2}$. About 43 percent of respondents who had paid for transport to the catchment facility said they could not afford the amount that it cost them. Those from Nyanza province were most likely to say they could not afford transport costs. About 21 percent of facility users, regardless of whether they paid for transport or not, said that they had delayed seeking care for their child because they could not afford transport costs.

About 86 percent of respondents who had patronized these facilities had paid consultation fees, ranging from 55 percent of those in Nairobi to 93 percent of those in Nyanza. The mean consultation fee across the sites was KSh 103, with a median of KSh 20, suggesting that there were a few respondents who had paid exceedingly high costs and are thus distorting the overall average (skewness). Among those who had to pay, 33 percent felt that the cost was unaffordable, including 61 percent of those in Nyanza. Nearly 25 percent of those using the facility had been forced to delay seeking care for their pediatric-age child because of the cost of consultation fees. This problem was particularly pronounced in Nyanza where 42 percent had delayed care.

Around 78 percent of those who had visited the facility said they had paid for drugs at their last visit, ranging from 54 percent of those who attended the Nairobi facilities to 82 percent of those who attended the Nyanza sites. Drugs were found to be more expensive than either transport or the consultation feethe mean cost was KSh 356, with a median of KSh 150, again indicating high skewness, with a small number of clients paying substantial amounts for drugs. The drug costs for those in Nyanza were more than 1.5 times the average cost of the other provinces. About half of those who had paid for drugs said that they found the cost unaffordable. Across all sites, 54 percent of all respondents attending the catchment facility said that they had delayed purchasing some of the prescribed drugs for their child because of cost in the preceding 12 months.

Taken together, total costs of transport, consultation fees, and drugs per visit reaches KSh 328 in Nairobi, KSh 215 in Eastern, and KSh 765 in Nyanza. These amounts represent a tremendous barrier to accessing services in Kenya, where half the population lives on less than KSh 70 per day (African Population and Health Research Center 2002).

${ }^{2}$ US\$1 = KSh 67 
Table 6 Cost and affordability of services at the catchment sites

\begin{tabular}{lcccc}
\hline & $\begin{array}{c}\text { Nairobi } \\
\mathbf{n = 4 6}\end{array}$ & $\begin{array}{c}\text { Eastern } \\
\mathbf{n = 2 7 7}\end{array}$ & $\begin{array}{c}\text { Nyanza } \\
\mathbf{n = 1 6 2}\end{array}$ & $\begin{array}{c}\text { All } \\
\mathbf{n = 4 8 5}\end{array}$ \\
\hline Transport (one way) & ${ }^{\dagger}$ & & & \\
Mean cost (KSh) & 6 & 21 & 29 & 22 \\
Median cost (KSh) & 0 & 20 & 30 & 20 \\
Range of cost (KSh) & $0-100$ & $0-200$ & $0-300$ & $0-30$ \\
\% paid for transport & 24 & 73 & 79 & 70 \\
\% found payment unaffordable (among paid) & 18 & 28 & 70 & 43 \\
\% have delayed care due to cost (among all) & 11 & 14 & 37 & 21 \\
Consultation fee last visit ${ }^{\dagger \dagger}$ & & & & \\
Mean charge (KSh) & 83 & 25 & 240 & 103 \\
Median charge (KSh) & 20 & 20 & 15 & 20 \\
Range of charges (KSh) & $0-600$ & $0-290$ & $0-12,000$ & $0-12,000$ \\
\% paid consultation fee & 55 & 85 & 93 & 85 \\
\% found it unaffordable (among paid) & 17 & 16 & 61 & 33 \\
\% have delayed care due to cost (among all) & 27 & 15 & 42 & 25 \\
Cost of drugs last visit ${ }^{\dagger \dagger}$ & & & & \\
Mean charge (KSh) & 160 & 243 & 558 & 356 \\
Median charge (KSh) & 20 & 150 & 150 & 150 \\
Range of charges (KSh) & $0-600$ & $0-2,000$ & $0-13,000$ & $0-13,000$ \\
\% paid for drugs & 55 & 80 & 82 & 78 \\
\% found it unaffordable (among paid) & 17 & 31 & 76 & 49 \\
\% have delayed care due to cost (among all) & 27 & 48 & 66 & 53 \\
Mean total cost (KSh) & $\mathbf{3 2 8}$ & $\mathbf{2 1 6}$ & $\mathbf{7 6 5}$ & $\mathbf{4 1 3}$ \\
(transport + consultation + drugs) & & & & \\
\hline
\end{tabular}

\footnotetext{
†Those who said "walking distance" or "0" were coded as "0."

${ }^{\mathrm{tt}}$ Those for whom consultation fee was free or waived were coded as "0." Excludes 23 respondents who did not know or could not recall the cost of consultation fee.

${ }^{\mathrm{ttt} T h o s e}$ for whom drugs were free or waived were coded as "0." Analysis excludes 127 respondents who said no drugs prescribed, can't recall cost, or drugs purchased elsewhere
}

The household survey continued to explore barriers to accessing care by asking all respondents about possible obstacles to visiting the health facility for their child and how frequently these factors might have played a role in decision-making (see Table 7: possible responses were "very often," "sometimes," or "never"). Across all sites, survey respondents indicated that transport costs had played a variable role in preventing them from accessing care for a child: in Nyanza, 69 percent of respondents said that a lack of money from transport had "sometimes" or "very often" prevented them from seeking healthcare for a child, whereas these responses were given by 33 percent of respondents in Nairobi and 17 percent in Eastern. Other barriers that had frequently played a role in preventing access to child health care facilities included inability to find a caregiver for other children (23 percent sometimes or very often across all sites) and a lack of time (16 percent sometimes or very often across all sites). Evidence continues to suggest that the attitudes of health providers deter 19 percent of all respondents across all sites sometimes or very often, most commonly in Nyanza (26 percent) and among male caregivers - this may be consistent with the findings reported above suggesting that clients in Nyanza were the most dissatisfied with the quality of the care that they had received. 
Table 7 Barriers to caregivers taking children to a health care facility in the past 12 months, household survey

\begin{tabular}{|c|c|c|c|c|}
\hline $\begin{array}{l}\text { Reason } \\
\text { (\% who have experienced the barrier } \\
\text { "sometimes" or "very often") }\end{array}$ & $\begin{array}{c}\text { Nairobi } \\
(n=375) \\
\%\end{array}$ & $\begin{array}{c}\text { Eastern } \\
(n=401) \\
\%\end{array}$ & $\begin{array}{c}\text { Nyanza } \\
(n=404) \\
\%\end{array}$ & $\begin{array}{c}\text { All } \\
(n=1,180) \\
\%\end{array}$ \\
\hline \multicolumn{5}{|l|}{ Lack of money for transport } \\
\hline Male & 30 & 16 & 69 & 39 \\
\hline Female & 35 & 18 & 70 & 41 \\
\hline All & 33 & 17 & $69^{*}$ & 40 \\
\hline \multicolumn{5}{|c|}{ Lack of caregivers to look after the other children } \\
\hline Male & 10 & 14 & 24 & 17 \\
\hline Female & 18 & 15 & 23 & 18 \\
\hline All & 14 & 15 & $23^{*}$ & 18 \\
\hline \multicolumn{5}{|l|}{ Unfriendly providers } \\
\hline Male & 10 & 15 & 31 & 19 \\
\hline Female & 20 & 18 & 22 & 20 \\
\hline All & 15 & 16 & $26^{*}$ & 19 \\
\hline \multicolumn{5}{|l|}{ Lack of time } \\
\hline Male & 19 & 19 & 17 & 18 \\
\hline Female & 19 & 15 & 11 & 15 \\
\hline All & 19 & 17 & 14 & 16 \\
\hline \multicolumn{5}{|l|}{ No permission from spouse } \\
\hline Male & 2 & 1 & 2 & 2 \\
\hline Female & 1 & 2 & 2 & 2 \\
\hline All & 2 & 1 & 2 & 2 \\
\hline
\end{tabular}

${ }^{*}$ Differences by sex statistically significant $p$ value at $p \leq 0.05$

The qualitative research provided further evidence of these obstacles. For example, although pediatric ARV drugs are officially provided free of charge, participants reported difficulty meeting the additional required costs of transport and prescription charges for treatment of OIs. Clients expressed dissatisfaction with services that claim to meet their needs but actually charge them additional fees for laboratory services or send them elsewhere to buy drugs (for OIs). Health workers acknowledged that in addition to expenses, clients found the process of seeking care to be long and demanding.

I have a prescription to go and buy drugs for my child but I don't have the money. This child needs medication immediately.

PLHIV support group member, Nyanza

By the time you go through cashier, registration, then to doctor, then to the laboratory, it is quite long, during which time they would like food and the things needed for the child.

VCT counselor, Nairobi

Health workers in Eastern province emphasized that transport costs were especially hard for elderly caregivers to meet. Other complaints involved the quantities of drugs: for example, a client in Nyanza noted that children's drugs had to be purchased in large and expensive quantities and could not be subdivided into smaller payment installments like adult formulations. 


\section{Hgrizons}

At the same time, there was dissent from health workers in Nairobi and HIV-positive participants in the Eastern and Nyanza sites, some of whom dismissed the importance of cost and transport as barriers discouraging service uptake, indicating that services are accessible but "some of us have not just thought of testing the children" (PLHIV support group member, Nyanza).

A further reported difficulty acting as a barrier to accessing pediatric HIV testing and treatment was in meeting the anticipated costs of food: clients were aware that a child or adult who goes onto ART will need to be assured of a sufficient diet to support their treatment, and they worried about their ability to meet the increased costs of the food required to support the renewed appetite of those on ART. This was particularly emphasized in Nyanza.

Some people fear taking children for HIV testing because they feel they will not afford the cost of sustaining an HIV-positive child. They know that people who are HIV-positive need improved diet which many parents believe they cannot afford. So they say they would rather not start a journey they will not accomplish. Instead, they watch the child get worse without attention and some finally die.

PLHIV support group member, Nyanza

Put together, these findings indicate that despite the official policy of free ART, cost remains a major barrier to seeking testing, care, and treatment for children who may be in need of pediatric HIV services. Even through ARVs are officially free, additional costs borne by caregivers include consultation fees, drugs for OIs, and transport. Evidence suggests that these barriers represent a significant obstacle causing as many as two thirds of clients in Nyanza to defer or delay care for their child.

\section{Knowledge about HIV and AIDS}

\section{HIV transmission}

Household survey responses indicated high awareness of HIV: virtually all (98 percent) respondents had heard or read about HIV and AIDS, and 92 percent were aware that children under the age of 15 years could be infected. About 30 percent believed there are "many cases of children with HIV in the community," including 23 percent of those in Nairobi, 22 percent of those in Eastern, and 44 percent of those in Nyanza.

Nearly all (99 percent) respondents who were aware that a child could be infected knew at least one method by which that could happen, but details were scant. Across all sites, 58 percent of respondents could name at least three ways by which a child under age 15 could be infected with HIV. The most common responses mentioned were contact with contaminated sharps (needles, razors) (55 percent), followed by children born of an HIV-positive mother (38 percent), sexual intercourse (34 percent), breast milk (33 percent), and during birth (30 percent).

These findings were supported by the qualitative research: FGD participants also elaborated on the risks faced by adolescent females, especially where poverty makes them vulnerable to transactional sex, child abuse, and having a sugar daddy, as well as the belief in virgin cleansing (i.e., the incorrect belief among some men that having sex with a virgin will cure them of HIV). Other participants also mentioned fears that children could be infected by HIV through other means, including sharing needles, instruments, razors (e.g., at the barber), and even school mathematical instruments; through domestic interactions (e.g., 
a cut in a household accident or a fight between children), contact with menstrual blood, and caregiving responsibilities. In Nyanza province, PLHIV support group members mentioned their fears that children caring for HIV-positive parents may have become infected through their caregiving tasks. Additional modes of HIV transmission to children mentioned reflected traditional practices including circumcision, the traditional practice of cutting the pharynx (mentioned in Eastern province), and the fear that traditional healers and traditional birth attendants may not use sterile equipment. Some incorrect modes such as sharing toilets or washing facilities were also mentioned. Evidence suggests that knowledge of the risks and realities of pediatric HIV transmission was in general superficial and that there is need to educate caregivers so they are better informed.

\section{Knowledge of symptoms of pediatric HIV disease}

The household survey further explored respondent beliefs about whether a healthy-looking child or adult could be HIV-positive. Nearly all (97 percent) caregivers said that a healthy-looking adult could be HIVpositive, while 87 percent said so of a healthy-looking child. Caregivers were also asked whether they knew any signs or symptoms indicative of HIV infection in a child: 51 percent could name at least three indications, and 73 percent (63 percent in Nairobi, 76 percent in Eastern, 80 percent in Nyanza) could name at least one.

Further knowledge was limited however: of the 13 possible signs and symptoms of HIV shown in Table 8 below, respondents could name a mean of 2.5 (3.0 in Nyanza, 2.5 in Eastern, 2.1 in Nairobi). Respondents most commonly mentioned frequent illness (47 percent), weight loss (41 percent), skin rashes and wounds (28 percent), unhealthy hair (24 percent), and listlessness (18 percent).

Table 8 Symptoms indicative of HIV in children under age 15 years mentioned by respondent, household survey

\begin{tabular}{lcccc}
\hline \% of respondents who mentioned... & $\begin{array}{c}\text { Nairobi } \\
(\mathbf{n = 3 4 6 )} \\
\%\end{array}$ & $\begin{array}{c}\text { Eastern } \\
(\mathbf{n = 3 6 5 )} \\
\%\end{array}$ & $\begin{array}{c}\text { Nyanza } \\
(\mathbf{n = 3 7 0 )} \\
\%\end{array}$ & $\begin{array}{c}\text { All } \\
(\mathbf{n}=\mathbf{1 , 0 8 1}) \\
\%\end{array}$ \\
\hline Frequent illness & 39 & 46 & 54 & 47 \\
Weight loss & 34 & 37 & 80 & 41 \\
Frequent skin disease (rashes, wounds) & 15 & 24 & 44 & 28 \\
Hair changes/thin and scattered hair & 15 & 20 & 35 & 24 \\
Weakness, listlessness, not fully conscious & 13 & 27 & 15 & 18 \\
Frequent/prolonged diarrhea episodes & 15 & 12 & 22 & 17 \\
Prolonged cough/tuberculosis & 19 & 15 & 17 & 17 \\
Skin changes/unhealthy looking skin & 12 & 17 & 21 & 17 \\
Failure to gain weight as expected & 12 & 14 & 6 & 11 \\
Failure to develop normally & 8 & 17 & 8 & 11 \\
Frequent fevers & 12 & 6 & 12 & 10 \\
White sores/ulcers in the mouth & 8 & 10 & 10 & 9 \\
Brain fever (meningitis) & 0 & 0 & 1 & 1 \\
\hline
\end{tabular}

*Multiple responses permitted 


\section{Hgrizons}

Community health workers were concerned that many of their clients were unaware of the signs and symptoms of pediatric HIV.

I think the other problem is ignorance. Many parents/caregivers do not know how to read HIVrelated signs in their children. They assume it is just any other attack from which the child will easily recover after attempted treatment such as seeking assistance from traditional doctors.

Community health worker, Nyanza

Qualitative data seemed to suggest that responses about signs and symptoms of HIV disease fell into three main categories:

a) Symptoms manifest in the child's physical health (e.g., delayed growth milestones, frequent and acute diarrhea, persistent respiratory infection, poor appetite).

b) Features of the child's family situation (e.g., a child with a parent known or suspected to be HIVpositive, a child that has been fostered into another household following parental death).

c) Psychosocial, behavioral, and other factors (e.g., an unhappy or isolated child, a child suspected to have been exposed through rape).

The FGDs further revealed that PLHIV support group members mostly focused on the family and behavioral aspects as indications that a child should be tested, while health workers and community health workers mostly focused on signs and symptoms of physical health. This suggests the need for health workers and community health workers to be sensitive to the concerns and motivations of their clients, while also increasing client and community education on common medical signs and symptoms to watch out for.

\section{Sources of information}

Household survey respondents indicated that health care providers (reported by 51 percent) were the most common sources of information on pediatric HIV infection, followed by radio (46 percent), print media (26 percent), family (20 percent), TV (19 percent), and church (16 percent; see Table 9).

Table 9 Source of information about pediatric HIV, household survey ${ }^{*}$

\begin{tabular}{lcccc}
\hline & $\begin{array}{c}\text { Nairobi } \\
\mathbf{n = 3 7 5} \\
\mathbf{\%}\end{array}$ & $\begin{array}{c}\text { Eastern } \\
\mathbf{n = 4 0 1} \\
\mathbf{\%}\end{array}$ & $\begin{array}{c}\text { Nyanza } \\
\mathbf{n = 4 0 4} \\
\mathbf{\%}\end{array}$ & $\begin{array}{c}\text { All } \\
\mathbf{n = 1 , 1 8 0} \\
\mathbf{\%}\end{array}$ \\
\hline Health care workers & 53 & 44 & 57 & 51 \\
Radio & 35 & 47 & 55 & 46 \\
Print media & 25 & 31 & 22 & 26 \\
Family & 23 & 19 & 18 & 20 \\
TV & 17 & 32 & 6 & 19 \\
Church & 13 & 21 & 15 & 16 \\
Barazas (community meetings) & 5 & 16 & 11 & 11 \\
School & 8 & 12 & 6 & 9 \\
Women's groups & 2 & 7 & 8 & 6 \\
\hline
\end{tabular}

*Multiple responses allowed 
The reliance on health workers was also documented among qualitative research participants, who further clarified that their main sources of knowledge about pediatric HIV was through contact with PMTCT or ANC services. A health worker in Eastern province observed that in communities with low ANC attendance or facility deliveries, knowledge of pediatric HIV is consequently lower. Knowledge of pediatric HIV was reported to be especially poor among grandparent caregivers.

\section{HIV Testing and Status Disclosure}

\section{HIV testing for children}

Almost all survey respondents (97 percent) said they would take their child for HIV testing if they suspected the disease (see Table 10). About 84 percent believed their partners would support this decision, with males more certain than females ( 87 percent vs. 81 percent). However, these gender differences were not statistically significant except for in Nyanza (95 percent vs. 87 percent, $\mathrm{p}=0.004$ ).

Table 10 Caregiver attitudes toward pediatric and family testing, household survey

\begin{tabular}{|c|c|c|c|c|}
\hline Percent who...: & $\begin{array}{c}\text { Nairobi } \\
\mathrm{n}=375 \\
\%\end{array}$ & $\begin{array}{c}\text { Eastern } \\
\mathrm{n}=401 \\
\%\end{array}$ & $\begin{array}{c}\text { Nyanza } \\
n=404 \\
\%\end{array}$ & $\begin{array}{c}\text { All } \\
\mathrm{n}=1,180 \\
\%\end{array}$ \\
\hline \multicolumn{5}{|c|}{ Would take own child for HIV testing if suspected } \\
\hline All & 98 & 95 & 97 & 97 \\
\hline Male & 98 & 94 & 95 & 96 \\
\hline Female & 98 & 96 & 99 & 98 \\
\hline \multicolumn{5}{|c|}{ Believes partner would accept having child tested } \\
\hline All & 79 & 81 & 92 & 84 \\
\hline Male & 84 & 81 & $95^{*}$ & 87 \\
\hline Female & 74 & 81 & $87^{*}$ & 81 \\
\hline \multicolumn{5}{|l|}{ Feels following should be tested: } \\
\hline Children under 15 years of age & 86 & 75 & 88 & 83 \\
\hline All children of HIV+ mothers & 94 & 93 & 97 & 95 \\
\hline All siblings of HIV+ children & 84 & 88 & 89 & 87 \\
\hline Mother of HIV+ child & 96 & 96 & 99 & 97 \\
\hline Father of HIV+ child & 97 & 96 & 98 & 97 \\
\hline Has had a child $<15$ tested for HIV & 14 & 7 & 10 & 10 \\
\hline \multicolumn{5}{|c|}{$\begin{array}{l}\text { Would tell someone if child in own household was } \\
\text { HIV+ }\end{array}$} \\
\hline All & 44 & 51 & 36 & 44 \\
\hline Male & $50^{*}$ & 56 & 35 & 47 \\
\hline Female & $39^{*}$ & 47 & 38 & 41 \\
\hline \multicolumn{5}{|c|}{$\begin{array}{l}\text { Would tell own older child (7-15yrs) if child was } \\
\text { infected }\end{array}$} \\
\hline All & 37 & 29 & 43 & 36 \\
\hline Male & 43 & 28 & 43 & 38 \\
\hline Female & 31 & 28 & 44 & 34 \\
\hline
\end{tabular}

${ }^{*} p \leq 0.05$ 


\section{Hgrizons}

Survey respondents also supported HIV testing for other family members: 83 percent said that all children under 15 years of age should be tested, and 87 percent felt that the siblings of an HIV-positive child should be tested. About 95 percent felt that all children of an HIV-positive mother should be tested, and 97 percent that all mothers and fathers of an HIV-positive child should also be tested.

In my opinion I see that if one has been tested and found to be positive, it's good for all the children to be tested despite of the age because you cannot know if one has or does not have.... If you suspect the child...it is good if they are tested.

PLHIV support group member

Many respondents in the FGDs expressed fear and concerns about testing children, and only 10 percent had had a child under 15 in their household tested (see Table 10). As some put it:

There's fear that if you propose the child be taken for HIV testing or treatment then you are the one who knows how the child got the virus. So both husbands and wives find it difficult to initiate the decision to take the child for HIV testing and treatment.

PLHIV support group member, Nyanza

Pregnant mothers are the ones that are usually very worried because they don't know what will happen with the child. Some prefer to die and leave behind a [presumed] negative child.

$\mathrm{MCH}$ nurse, Eastern

Research participants expressed fear of multiple negative consequences if a child was found to be HIVpositive: they feared that their confidentiality would be jeopardized by health workers and that health workers would not show them understanding and sympathy. Furthermore, they were scared to face the potential consequences of an HIV-positive diagnosis for their child, including the fear that the child would not survive long, and a fear of the drugs and care burden for both child and parent. In addition, they were also afraid of the stigma that both parent and child would face, since revealing the infant to be HIV-positive would by extension reveal at least the mother be HIV-positive, thus exposing them to stigma and allegations of sexual misbehavior or unfaithfulness to their spouse, and forcing them to face their own treatment needs.

Some people just fear knowing their status that someone will think they are promiscuous. The same is true if their little children test HIV-positive because people will know the children acquired the virus from them [parents]. I know people who have come up to the door of the VCT [clinic] and went back without testing because of fear.

PLHIV support group member, Nyanza

Health workers acknowledged the allegation of breached confidentiality and were vigorously defensive in their response to it, claiming that such breaches were due to other clients and not clinic staff.

No, I don't think it is the health workers breaching confidentiality. It is the patients themselves who talk about one another once they learn so and so are taking HIV drugs. The patients on treatment are the ones spreading rumors, not the health workers.

Community health worker, Nyanza 
Female participants reported various difficulties in seeking support from their spouse for testing a child for HIV. Many reported great reluctance from their male partner to test the child for HIV, unless the child was visibly sick. Even harder was to convince the male partner to go for testing himself.

Most men dislike to be tested. Until when the situation is worse, that is when they agree to be tested, but [before that] if you suggested that he should be tested, he could even have chased you out of his house.

Moderator: What if you tell him that the child is supposed to be tested?

He tells you there is nothing of the sort.

PLHIV support group member, Eastern

I think it's not easy for spouses to support each other on HIV testing for children. The same couples cannot agree to test themselves, how will they support each other in children testing? It's not easy. ...but mothers are fast to consent for such tests without involving the father. But if the test result is positive, the mother brings the father in and arguments may follow on how the child could have contracted the virus.

PLHIV support group member, Nyanza

Today I had two parents, the mother and the father, just to consent that we test the child the father was reluctant. After result was positive, I tried to talk with the husband-he was not ready for it and started blaming the mother and distancing himself. You would think he has never been near them before.... ... ratio of mothers accepting testing is higher than that of fathers accepting testing.

Health worker (Nursing Officer), Nyanza

Community health workers raised concerns that some caregivers believe that the doctors may deliberately inject patients with HIV.

Caretakers believe that doctors inject and infect people with the virus. But we are continuing to educate and encourage them to come for testing and be educated on the service. For children we will continue to inform them there are services in this facility starting from five years and below... and for older children under 15. But it is difficult.

Community health worker, Nairobi

\section{Disclosure of child's HIV status}

The household survey explored respondents' attitudes toward HIV status disclosure, under the hypothetical circumstances that a child in their household was discovered to be HIV-positive Less than half (44 percent) said they would disclose to someone other than a health worker (see Table 11). In Nairobi and Eastern provinces, men were more likely to say they would disclose than women. Given the choice of which person they would choose to disclose to (shown in Table 11), the most common response was the spouse, although significantly fewer female respondents than male indicated that they would reveal the child's HIV status to their partner. 


\section{Hgrizons}

Table 11 Who caregivers would disclose child's HIV status to other than health worker, household survey

\begin{tabular}{lccc}
\hline & $\begin{array}{c}\text { Male } \\
(\mathbf{n = 2 6 3 )}\end{array}$ & $\begin{array}{c}\text { Female } \\
(\mathbf{n = 2 5 3 )}\end{array}$ & $\begin{array}{c}\text { All } \\
\text { (n= 516) } \\
\%\end{array}$ \\
\hline Spouse/partner & $81^{* *}$ & 71 & 76 \\
Child's parent & 8 & 11 & 9 \\
Child's grandparent & 23 & 21 & 22 \\
Child's uncle/aunt & 21 & 21 & 21 \\
Child's siblings & 6 & 8 & 7 \\
Child's teacher & 6 & 4 & 5 \\
Religious leader & 7 & 8 & 7 \\
Counselor & 7 & 10 & 8 \\
Friends & 14 & 15 & 15 \\
\hline
\end{tabular}

${ }^{* *} p \leq 0.01$

Respondents were also asked whether they would inform an older child, aged between 7 and 15 years, about the child's HIV status were he or she found to be HIV-positive. Again, respondents were reticent, and only 36 percent said they would, with men in Nairobi being the most likely to say so.

During the qualitative research, opinions among PLHIV support group members about disclosure of HIVpositive status to the child were generally divided - they outlined some of the benefits (e.g., access to services, easier to discuss having safer sex, learning from each other to live positively) and some of the drawbacks (e.g., exposure to stigma and abuse, feeling discouraged). However, many participants acknowledged that as children grow older, they will find out their own HIV status, as they begin to question why they are taking so many drugs. Parents expressed fear that as children find out that they are HIV-positive, it will lead them to wonder about their parents' sexual behavior. Participants felt that disclosure ought to be done by a parent but with support available from health workers where necessary, emphasizing the importance of careful and age-appropriate counseling.

Ifeel the status of these children should be hidden so that their peers do not use their status abusively against them. This may discourage them from taking the medication, and this might lead to death if the medication is not taken consistently.

PLHIV support group member, Nyanza

Don't reveal to the child his HIV status. He will be psychologically tortured and this will be a mark of injury in his mind and his entire life as a person. He will be psychologically destroyed and will never make any attempts to develop himselffor future life because he has no future to build. In his mind, he's a good-for-nothing person. It will be a curse in his life, so do not try. Just give the necessary drugs but maintain confidentiality.

PLHIV support group member, Nyanza 


\section{Caregivers' HIV testing behaviors}

In order to shed further light upon caregiver attitudes toward HIV testing, household survey respondents were also asked about whether they and their partners had been tested for HIV (see Table 12). Results highlight the differential between the uptake of HIV testing among males and females: while 63 percent of female caregivers had been tested for HIV, only 39 percent of male caregivers indicated that they had been tested. These results reflect the greater availability of HIV testing to women through antenatal clinic settings and indicate a need to offer HIV testing to males. Increased awareness of HIV among fathers may facilitate willingness to test children and reduce blame-seeking when mothers are more commonly the first to discover a child's HIV-positive status.

For both males and females, caregivers in Nairobi were more likely to have been tested for HIV than caregivers in Eastern and Nyanza. Among those who had been tested for HIV, around half had been tested within the last year, again with higher levels in Nairobi.

Table 12 also illustrates individuals' awareness of whether or not their partner has been tested for HIV. Overall, across all sites, it appears that there is reasonable concordance between whether women think that their male partner has been tested and reported levels of testing among males; but greater divergence between whether men think that their female partner has been tested and reported levels of testing among females. These data reinforce the need for couple counseling and family HIV testing programs to increase status awareness and facilitate communication about HIV testing.

Table 12 Caregivers' awareness of their HIV status, household survey

\begin{tabular}{|c|c|c|c|c|}
\hline Percent who... & $\begin{array}{c}\text { Nairobi } \\
n=375 \\
\%\end{array}$ & $\begin{array}{c}\text { Eastern } \\
\mathrm{n}=401 \\
\%\end{array}$ & $\begin{array}{c}\text { Nyanza } \\
n=404 \\
\%\end{array}$ & $\begin{array}{c}\text { All } \\
\mathrm{n}=1,180 \\
\%\end{array}$ \\
\hline \multicolumn{5}{|c|}{ Have been tested for HIV } \\
\hline All & 68 & 45 & 42 & 51 \\
\hline Male & $51^{*}$ & $32^{*}$ & $35^{*}$ & $39^{*}$ \\
\hline Female & $81^{*}$ & $58^{*}$ & $49^{*}$ & $63^{*}$ \\
\hline \multicolumn{5}{|c|}{$\begin{array}{l}\text { Been tested in past year (among those who have } \\
\text { been tested, } n=603 \text { ) }\end{array}$} \\
\hline All & 59 & 43 & 54 & 53 \\
\hline Male & 55 & 44 & 56 & 52 \\
\hline Female & 61 & 42 & 53 & 53 \\
\hline \multicolumn{5}{|c|}{$\begin{array}{l}\text { Say partner has been tested (among those with a } \\
\text { partner, } n=1,012 \text { ) }\end{array}$} \\
\hline All & 58 & 43 & 37 & 46 \\
\hline Male & $68^{*}$ & $51^{*}$ & $40^{*}$ & $52^{*}$ \\
\hline Female & $48^{*}$ & $35^{\star}$ & $32^{*}$ & $39^{*}$ \\
\hline
\end{tabular}

${ }^{*}$ Sex differences significant at $p \leq 0.05$

\section{Disclosure of caregiver's HIV status}

The household survey asked respondents about their attitudes toward disclosing their own HIV status to a child aged 10-15, under the hypothetical circumstances that they discovered they were HIV-positive: 41 


\section{Hgrizons}

percent of males and females alike said they would disclose, and 56 percent said they would not. Those who would be willing to disclose to their children said they would do so in order that the children know (72 percent), so that the children can be careful when caring for their parent or guardian ( 25 percent), and so that they can prepare for their demise ( 21 percent). The main reason for not disclosing was to avoid distressing the children with such information, reported by 57 percent of those not willing to disclose. The other major reasons were that the child was too young ( 39 percent), may tell others ( 26 percent), fear of shame ( 22 percent), fear of stigma (18 percent), that they would not know how ( 9 percent), and fear of discrimination (7 percent).

If you tell the child you are HIV-positive, you have exposed your nakedness to the child because the common belief is that HIV is sexually transmitted. The child begins to imagine how sexually irresponsible his parents are. Let the child hear my status as rumors but not myself telling him. PLHIV support group member, Nyanza

\section{Pediatric Antiretroviral Treatment}

\section{Caregiver treatment literacy}

In order to explore respondent treatment literacy concerning pediatric HIV, survey respondents were asked to respond to a series of statements about pediatric treatment (see Table 13). Data show that 71 percent of respondents were aware of the possibility of pediatric HIV treatment, with females (76 percent) significantly more likely to be aware than males (66 percent). The sex differentials were particularly significant in Nairobi and Nyanza. Most respondents ( 82 percent) were also aware that with proper medication, HIV-positive children could live up to adulthood, and again women ( 86 percent) were more likely to say so than men (79 percent). About two-thirds were aware that medication for treating children was now available for free in public sector facilities in Kenya, again with women (72 percent) more aware of this fact than men (62 percent). About three-quarters were aware that ARVs could reduce OIs among children (72 percent among men and 79 percent among women). However, only half the respondents knew for how long an infected child should be on AIDS medication (the correct answer was "for life" or "as prescribed by the doctor"), with no gender differentials. These data indicate variable awareness about HIV treatment for children across the study sites, with women consistently more likely to be betterinformed than men.

FGDs allowed for further probing of treatment literacy and revealed worries among community members. One major concern was the perceived unsustainability of treatment, a factor that discouraged some from initiating their children on ART.

They believe that children on ART will finally die once the supply of ART is curtailed. Also, the worry that ART may not be there forever discourages some parents/caregivers from starting their children on a product whose sustainability they are not assured of.

PLHIV support group member, Nyanza

I would like to add that some parents are worried. They are imagining what it would be like should the new government stop giving ARVs for free. Caregivers know that the end result is death should this government stop free ARVs because on their own, most caregivers cannot afford the cost of ARVs. 
Table 13 Treatment literacy among household survey respondents

\begin{tabular}{|c|c|c|c|c|}
\hline Percent with correct answer & $\begin{array}{c}\text { Nairobi } \\
\mathbf{n}=375 \\
\%\end{array}$ & $\begin{array}{c}\text { Eastern } \\
\mathrm{n}=401 \\
\%\end{array}$ & $\begin{array}{c}\text { Nyanza } \\
\text { n = } 404 \\
\%\end{array}$ & $\begin{array}{c}\text { All } \\
n=1,180 \\
\%\end{array}$ \\
\hline \multicolumn{5}{|c|}{$\begin{array}{l}\text { There is treatment for children with HIV } \\
\text { (Correct response: true) }\end{array}$} \\
\hline All & 75 & 65 & 73 & 71 \\
\hline Male & $68^{*}$ & 64 & $66^{*}$ & $66^{*}$ \\
\hline Female & $81^{*}$ & 66 & $80^{*}$ & $76^{*}$ \\
\hline \multicolumn{5}{|c|}{$\begin{array}{l}\text { Children with HIV can live to be adults if they take } \\
\text { medications as advised by HCW } \\
\text { (Correct response: true) }\end{array}$} \\
\hline All & 89 & 81 & 78 & 82 \\
\hline Male & $83^{*}$ & 80 & 74 & $79^{*}$ \\
\hline Female & $93^{*}$ & 82 & 82 & $86^{*}$ \\
\hline \multicolumn{5}{|c|}{$\begin{array}{l}\text { Treatment for children with HIV is free in public } \\
\text { health facilities in Kenya } \\
\text { (Correct response: true) }\end{array}$} \\
\hline All & 70 & 63 & 70 & 67 \\
\hline Male & 66 & 61 & $62^{*}$ & $62^{*}$ \\
\hline Female & 73 & 64 & $78^{*}$ & $72^{\star}$ \\
\hline \multicolumn{5}{|c|}{$\begin{array}{l}\text { ARVs reduce the risk of Ols among infected children } \\
\text { (Correct response: true) }\end{array}$} \\
\hline All & 78 & 80 & 68 & 75 \\
\hline Male & 75 & 79 & 63 & $72^{*}$ \\
\hline Female & 80 & 81 & 73 & $79^{*}$ \\
\hline \multicolumn{5}{|c|}{$\begin{array}{l}\text { Know how long a child should be on ART } \\
\text { (Correct responses: for life, or as advised by health } \\
\text { worker) }\end{array}$} \\
\hline All & 445 & 62 & 46 & 51 \\
\hline Male & 49 & 67 & 41 & 59 \\
\hline Female & 42 & 57 & 48 & 49 \\
\hline
\end{tabular}

*Sex differences significant at $p \leq 0.05$

Because many parents bring their children to health clinics after HIV disease is far advanced, there was an association between ART and mortality. As health workers in Nyanza commented:

Another fear when starting ART, the caregiver may have seen a child on ART die, and they fear that this one may also die like the other one who was on ARVs.

Laboratory technician, Nyanza

Community health workers noted that caregivers were uninformed about ARVs and were suspicious of treatment; they requested programs to educate caregivers, including information on the more subtle and difficult aspects of treatment, such as the varying disease progression and individual response to treatment.

The problems with the caretakers, they don't believe that a person improves.

Community health worker, Nairobi 


\section{Hgrizons}

While community members were increasingly aware of HIV treatment among adults, many were still learning about HIV treatment among children. A health manager in Nairobi noted that all available communications materials about treatment described treating adults and that there were no materials that addressed the situation of children on treatment.

\section{Most of them do not know there are ARVs for children.}

Health worker (Community health nurse, Maternity department), Nyanza

Some community health workers and PLHIV support group members reported confusion about the changing protocols, and others struggled to understand the difference between administering prophylaxis and treatment for OIs and administering ARVs. Comments from others reflected persistent misconceptions about ART (e.g., it will reverse a child's HIV status from positive to negative). However, the qualitative research also documented that community health workers and PLHIV support group members had some limited awareness about treatment issues, e.g., knowing that not all HIV-positive children need ARVs immediately.

Some can be given ARVs but others who are still strong just get treatment for OIs. But either way, the child should get relevant treatment for his condition.

PLHIV support group member, Nyanza

No, not all [HIV-positive children should be on ARVs]. Some still have strong body defense and can just be given treatment of opportunistic infections. Not all children who are HIV-positive should be on ART.

PLHIV support group member, Nyanza

Before we used to take care of adults, they never used to test children. So when a child came and suspected she/he is infected with HIV, they used to give Septrin until the child reaches a certain age so as to be tested. ...children never used to get ARVs. But now they are tested and get the ARVs.

Community health worker, Nairobi

I would like to point out that there is some difficulty.... We [community health workers] need more training on what are the signs that the child is positive but looks healthy? We should be educated on the emerging HIV issues and new HIV interventions. Previously we were told young children should not be taken for VCT. Again we are told children can now be taken to VCT for an HIV test. We need more training to understand these changes.

Community health worker, Nyanza

At all sites, some community members and $\mathrm{CHW}$ sere aware of children in their community who were on treatment, and had witnessed their dramatic improvements on ARV treatment.

You can go and look at that child, you see the way he was before, maybe he was very weak and now he has started to gain strength...he was weak and when other children were playing he was not. But as he goes on to take the drugs and goes on to eat well, you see that there are benefits because this child feels healthy. He can also go to the other children and they can play just outside the house.

Community health worker, Eastern 
When household survey respondents were asked if they knew where they could go for pediatric HIV testing and treatment services (see Table 14), less than two-thirds (64 percent) were aware of such a facility - a finding that is particularly disturbing in light of the fact that the study sites were all located within $5 \mathrm{~km}$ of such a facility. Those in Nairobi were consistently least likely to be aware (46 percent), followed by those in Eastern province (64 percent), while those in Nyanza were most likely to be aware (81 percent). There were minimal sex differences in this regard.

Table 14 Awareness and perceived affordability of pediatric testing and treatment services, household survey

\begin{tabular}{|c|c|c|c|c|}
\hline Percent who...: & $\begin{array}{c}\text { Nairobi } \\
\mathrm{n}=375 \\
\%\end{array}$ & $\begin{array}{c}\text { Eastern } \\
n=401 \\
\%\end{array}$ & $\begin{array}{c}\text { Nyanza } \\
\mathrm{n}=404 \\
\%\end{array}$ & $\begin{array}{c}\text { All } \\
\mathrm{n}=1,180 \\
\%\end{array}$ \\
\hline \multicolumn{5}{|c|}{$\begin{array}{l}\text { Know where to get HIV testing and treatment for } \\
\text { their child under age } 15\end{array}$} \\
\hline All & 46 & 64 & 81 & 64 \\
\hline Male & 43 & 64 & 80 & 64 \\
\hline Female & 49 & 63 & 82 & 64 \\
\hline \multicolumn{5}{|c|}{$\begin{array}{l}\text { Believe they can afford testing and treatment for } \\
\text { their child, among those who know where to get it } \\
(n=755)\end{array}$} \\
\hline All & 57 & 54 & 65 & 60 \\
\hline Male & 54 & $50^{*}$ & $54^{*}$ & $53^{*}$ \\
\hline Female & 61 & $57^{*}$ & $75^{\star}$ & $66^{\star}$ \\
\hline
\end{tabular}

${ }^{*}$ Sex differences significant at $p \leq 0.05$

Those who were aware of a facility were asked whether they thought they could afford the services there and 60 percent said they could, or that the services were free. Women were more likely than men to feel that they could afford those services (66 percent vs. 53 percent, $\mathrm{p}<0.001$ ). Caregivers from Nyanza were most likely to say they could afford services or that they were free ( 65 percent), followed by those in Nairobi (57 percent) and Eastern (54 percent).

\section{Getting it right: Administering pediatric treatment}

CHWs and PLHIV support group members were well aware of the difficulties inherent in administering pediatric HIV treatment. They cited a range of unpleasant side-effects of pediatric ART including dizziness, nausea, vomiting, anemia, swollen stomach, disfiguring skin rashes, insomnia, drowsiness, forgetfulness, and lack of appetite - although some acknowledged that these improved with time. In light of these side effects, they emphasized the importance of follow-up care and adherence support through clinics and CHWs. 


\section{Hgrizons}

Like this one, she is a big child and has skin rashes because at times they become septic and we have to use gloves and other things.... At times she is stared at so much you see she gets discouraged. She does not want to be among other girls, so you see that is a challenge.

PLHIV support group member, Eastern

And if it is a child, he/she will not say that the feet are itchy or I have a headache. There are those signs that you will see and understand what problem the child has. So ARVs have their own side effects.

PLHIV support group member, Nairobi

Participants also acknowledged the difficulty of administering the pediatric ART regimens. Elderly caregivers in particular reported difficulty with timing and measuring correct dosages. While CHWs explained how they provided support to such caregivers, especially those whose vision was impaired (e.g., by clearly marking bottles), they expressed frustration with the existing formulations available and lamented that an injection would be much easier to administer than complicated tablets requiring cutting or even syrups requiring refrigeration and measuring. Acknowledging varying caregiver attitudes toward adherence, participants observed that the most successful children on treatment were those whose caregivers were extremely motivated to maintain treatment adherence. Other difficulties with the drugs included what to do when the child vomits their drug, questions about challenging drug combinations, how to respond to children complaining of the drugs' bitter taste, and the inability to meet the increased appetites of children on ART. Furthermore, health workers recognized that it may be difficult for caregivers to meet the storage demands of the drugs requiring refrigeration.

Some may forget, others may give later time, and other times they give out overdose by giving more than expected. Others have to wait for somebody who may have the knowledge of the right dosage and this person may not be always there. Also bitter-tasting drugs are a problem to children.

Community health worker, Eastern

Taking care of children with HIV is difficult especially for a widow like me who is the sole caregiver. You may not have the necessary resources to enable you meet the demands of care. The child needs good food (balanced diet) and clean sleeping place. You also need to keep medication consistent. Such a child may also need to take at least one glass of milk each day and this may not be [easy] for a caregiver/parent whose income is minimal.

PLHIV support group member, Nyanza

The child used to complain the drugs were bitter when he started using them and we would let him swallow the drugs with porridge. But after he got used to them, he now uses water to swallow drugs. Initially, the drugs would make him nauseated and he wants to vomit but even that feeling is now gone and he's taking the drugs normally. Again the fact that he had to take different kinds of drugs many times per day was a burden to him. We would try to force him. Sometimes he would just leave the home to go and play somewhere else so that he is not available to take the drugs at the time required. So, we (I or my wife) had to look for him. Because of that we cannot boast of having given all the medication in time.

PLHIV support group member, Nyanza

Participants also reported that caregivers had difficulty internalizing the fact that the child needed to stay on treatment for the rest of their life. The unwelcome prospect of lifelong treatment commonly introduces new obstacles to adherence, including the possibility that caregivers will cease administering treatment as 
soon as the children look like they are improving. Opinions varied as to whether children's treatment adherence was better if they had a parent or caregiver who was also on treatment: some argued that a parent on ART themselves was likely to be more attentive and understanding of the child's needs, while others argued that the dual treatment burden was simply overwhelming.

Discussions, especially in Nairobi, also emphasized that poverty and insecure living arrangements bring additional obstacles to treatment adherence or accessing care, especially for children whose parents have died. Poor households may find it difficult to support the increased nutritional requirements of children on ART.

Actually food scarcity is a real challenge in this community because they usually are families that are headed by mothers; because some work for others to get food for that day. So once the children are left even to take the medicine while hungry they don't.

Community nurse, Nairobi

Only medicines [are available] but the children are dying of hunger.

PLHIV support group member, Nyanza

People are very poor. Sometimes some of them walk all the way and they have to sit and queue for a long time. In the end, after being attended, they walk home, which is several kilometers away, tired and hungry...even the children.... I wish we could find a means of offering them a small meal while they wait here. It would really help them come....

Health manager, Nyanza

\section{Attitudinal Barriers to Accessing Care}

\section{Stigma}

To assess the extent to which stigma could be a barrier to care, household survey respondents were asked to respond to a series of statements and questions regarding stigma (see Box 1). 


\section{Hgrizons}

\begin{tabular}{|l|}
\hline Box 1 Stigma questions \\
\hline $\begin{array}{l}\text { If you found out that a child in your household was infected with HIV/AIDS, would } \\
\text { you tell anyone, apart from a health worker? }\end{array}$ \\
\hline $\begin{array}{l}\text { If you found out that a child living in your household was HIV-positive: } \\
\text { Would you let him/her stay in your household? } \\
\text { Would you be responsible for his/her treatment? } \\
\text { Would you allow him/her to go to school? }\end{array}$ \\
\hline $\begin{array}{l}\text { If one of your child's classmates at school was HIV-positive, would you ask the } \\
\text { school authorities to stop that HIV-infected child from attending school? }\end{array}$ \\
\hline $\begin{array}{l}\text { Do you agree or disagree with the following statements: } \\
\text { HIV among children is a punishment for the bad behavior of their parents. } \\
\text { Children who are HIV-positive should be separated from other children. } \\
\text { Parents of children with HIV should be ashamed of themselves. }\end{array}$ \\
\hline
\end{tabular}

Some examples of the results are presented in Figures 3 and 4, while the remaining questions showed similar trends. Across the three sites, nearly 60 percent of caregivers indicated that they feel that HIV among children is punishment for bad parental behavior, and 31 percent felt that the parents of HIVpositive children should be ashamed of themselves.

\section{Figure 3 Percent of caregivers who agree that HIV among children is punishment for the bad behavior of parents, household survey}

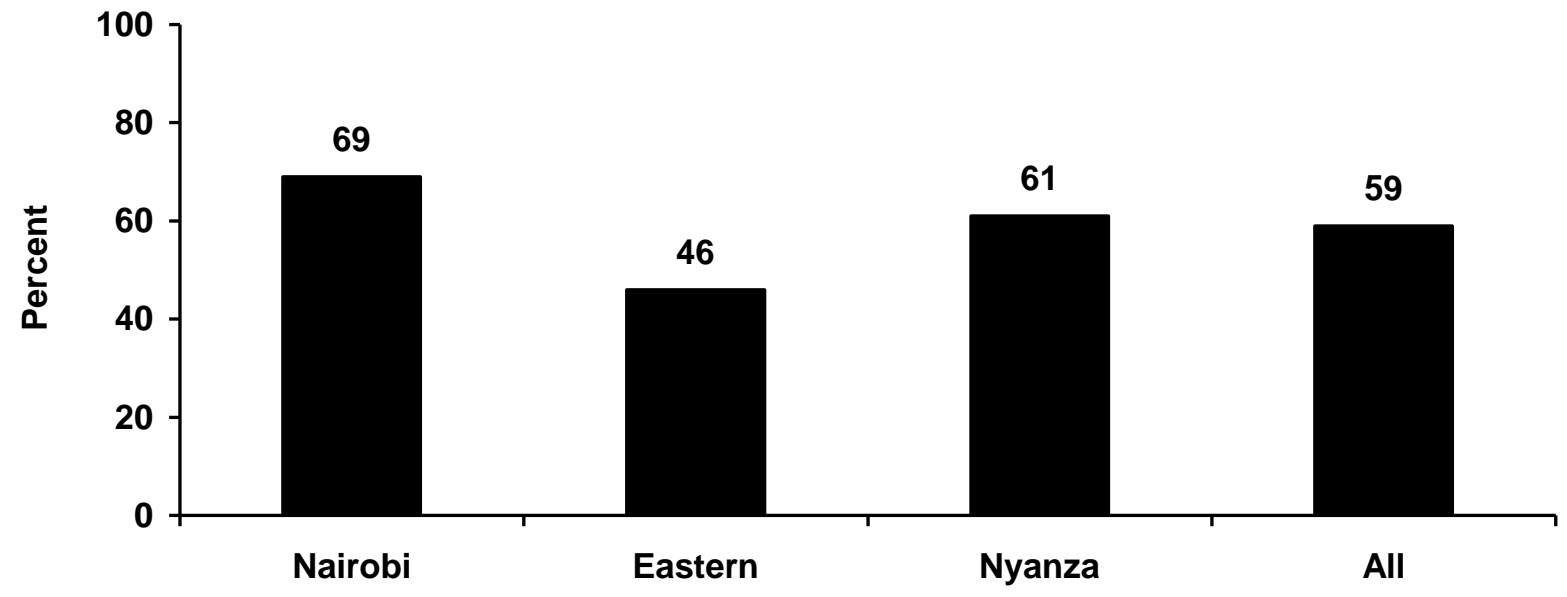




\section{Figure 4 Percent of caregivers who agree that parents of HIV+ children should be ashamed of themselves, household survey}

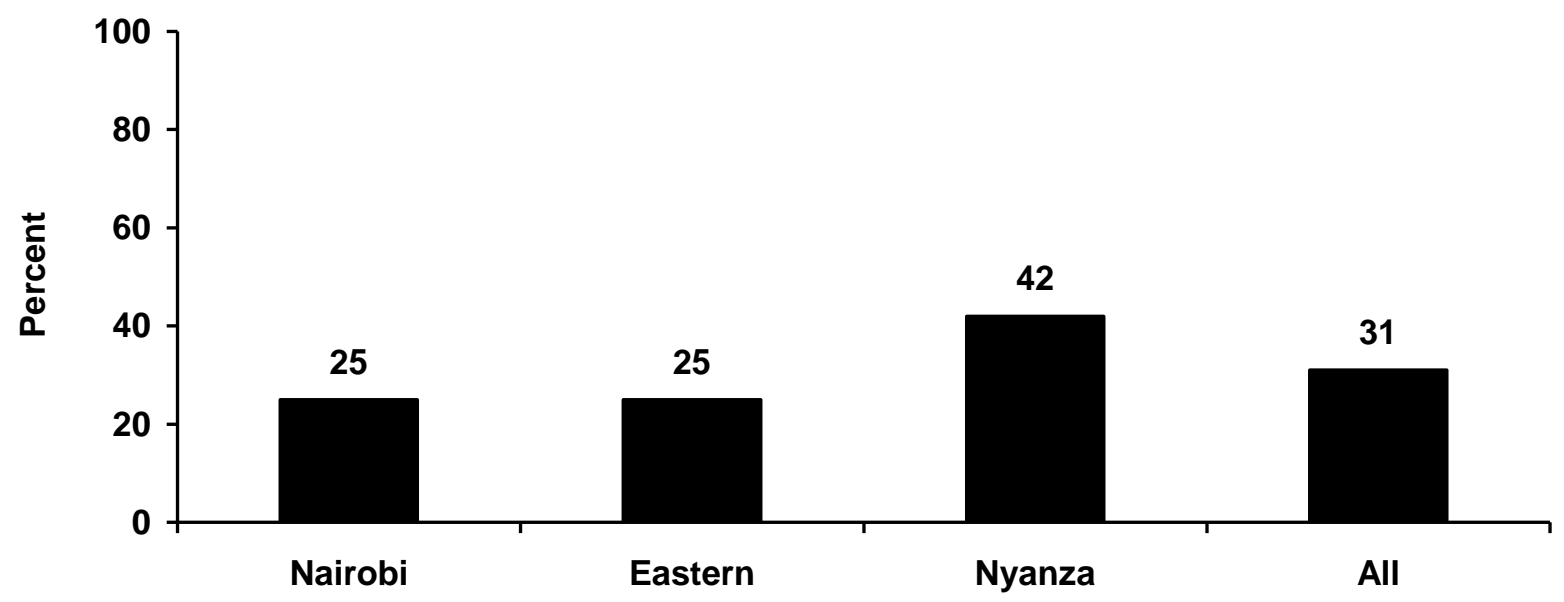

Respondents demonstrated attitudes largely supportive of HIV-positive children: 83 percent believed that HIV-positive children should be allowed to remain within the household and not be separated from others; 91 percent of caregivers said they would allow an infected child to remain in their household without any conditions; 86 percent said they would take unconditional responsibility for the child's treatment; 92 percent said they would unconditionally allow the child to go to school; and 93 percent said they would not ask the school to keep an HIV-positive classmate of their child away from school.

Findings from the qualitative research support these survey findings: community members reported that infants known to be HIV-positive are regarded with sympathy, as victims of the consequences of their parents' promiscuity. Parents, on the other hand, are regarded as blameworthy for their irresponsible sexual behavior.

Many people sympathize with the child as a victim of circumstances if the child is young. You can hear someone say, "It is not the child's wish to be what he is." The community feels it's the parents who put the child in this condition if the child is born with the virus.

PLHIV support group member, Nyanza

Older HIV-positive children and adolescents attract less empathy however, and face suspicion that they contracted the virus through sexual transmission. HIV may sometimes be seen as appropriate punishment for them.

People see [infected children] as victims of their parents' bad sexual behavior if they are young, but if adolescents, as bad boys or girls.

Community health worker, Nyanza

Stigma within the household may also lead to neglect or abuse, and affect children's access to treatment. Participants in the Eastern and Nairobi sites reported that some HIV-positive children, especially those fostered in a new household following parental death, may be forced to use separate plates and utensils, to sleep in a separate area, and to wash their clothes separately. 


\section{Hgrizons}

Stigma, especially for the big children that don't live with their parents... when they come, you see the child is been mistreated. The [caregivers] think the child will only die, so they feel why should they take care? They don't give [the child] drugs, especially if the child is on ARVs....

Pharmaceutical technician, Nairobi

However, participants at multiple sites reported that the situation may be improving, due to community outreach campaigns raising awareness and counseling.

Previously we feared that if I and my child are HIV-positive the villagers will see me and my family as finished, that my household is gone. Also being branded "Ja Ayaki" [someone with AIDS] is not easy to internalize. But after counseling and being given hope that I and my child can take drugs and live on, the fear of stigma has since grown wings and flew away.

PLHIV support group member, Nyanza

When clinics become locally known for providing services to HIV-positive adults and children, facilitybased stigma was said to further prevent people from accessing services, as people became uncomfortable being seen there. This is particularly the case in the Nairobi sites, which are openly known to serve HIVpositive individuals. A CHW reported that some of their patients did not want to be seen receiving a household visit:

I have a client with two children. I have tried to take a nurse to her house. She said she doesn't want to be visited; she doesn't want the neighbors to know she uses drugs.

Community health worker, Nairobi

PLHIV support group members in the Eastern and Nairobi sites reported that parents may take their older children to be tested for HIV without telling them what they are being tested for, out of fear of stigma. Such attitudes indicate lack of awareness among the community about long-term survival with HIV.

\section{Fatalism and loss of hope}

One of the topics that emerged spontaneously and powerfully from the qualitative research was the prevalence of fatalistic attitudes: the belief that with or without treatment, children who are HIV-positive are a lost cause. Many community members reported fatalistic beliefs that such children will inevitably die at a young age, leading to pessimism about their future prospects. This in turn was reported to lead to neglect and discrimination toward the children, and reluctance to invest any resources into their treatment and care. Other FGD participants reported the fear of prolonged trauma as caregivers and family members witness a child's prolonged and painful illness and death. These comments underscore the important educational role of the CHWs in addressing such attitudes and educating community members about treatment options and prospects.

Many of these parents believe that child will die. ...she sees now there is no need of being concerned more than that, maybe she will stay with him for a few days then he dies. So our challenge [as community health workers] is very big, that is to ask this mother to take the child for testing, because it does not mean that the child is positive. And if positive it does not mean he will die at that moment. He can even stay for many years. But they see just that the child will die. Female community health worker, Eastern 
Some do not see why [they should] seek medical help, and the child is suffering in pain. In fact, some say if you eliminate pain, the sooner the patient goes the better; why not let the child go quickly? Since there is no need to suffer and the child is going to die soon anyway.

Female nurse, outpatient department, Nyanza

Another worry for caretakers is that they are worried about depletion of resources. They worry that all the available family wealth will be sold to enable the child get treatment, but finally the child will just die. So there's the feeling of worthless wastage of resources.

Community health worker, Nyanza

With limited awareness of the life expectancy of HIV-positive children, a common assumption in the community is that if a child survives to over two or three years of age, they must be HIV-negative. This focus on younger children prevents caregivers - especially grandparents - from bringing in older children for HIV testing.

Some time ago, people used to say a child above 3 years cannot be HIV-positive.

VCT counselor, Nairobi

They [caregivers] do not expect that a child born HIV-positive will live very long. I think for them they are even shocked that the child is negative. I think maybe only one or two people believe that a child can live for that long. So from the way they respond when you tell them to bring the older children, below thirteen or fifteen years, for testing, they are like, do you mean that if they have HIV they can live for that long? So you can already feel that they do not associate that kind of long life with HIV. [Another participant agrees]

Female nurse, Nairobi

Some evidence emerged that some of these attitudes may originate from the health care facilities, supported by community members and community health workers:

Then [the] doctor told me that the child will not go beyond five years. Now I was left there waiting for the child to die, I lost hope in life. I wasted almost three years waiting for death. And [the child] is still alive.

PLHIV support group member, Eastern

I want to say expressly that health providers are careless. Right now as we talk I have a patient at this hospital who is admitted. The child is seven months old. The day I brought the child here, a health provider told me that I have already killed the child so I just take it back home. I was told, "You have already killed the child for the past two months, what do you want us to do to it, you better take it back home." Another nurse added, "We cannot waste oxygen on this one." But the same child is alive to date. I am now making arrangements to take him home, he's now discharged. So, such responses kill people's spirits and discourage access to health services. Health providers need training on communication.

Community health worker, Nyanza

Health workers stressed the role of adherence counseling for children on treatment, including support in the community from CHWs. They also stressed the need for parents and caregivers to be hopeful and not dwell upon thoughts of the child's death. However, while parents can be hopeful for their individual family members, the community in general is not optimistic about the prospects of survival for HIV- 


\section{Hgrizons}

positive children. Health workers and CHWs acknowledged that they have an important role to play in encouraging the optimism that favors continued treatment adherence in the face of such attitudes.

Due to much counseling that we are doing, those who are on treatment believe there is now life ahead of them.

Community health worker, Eastern

Before we didn't have those ARVs but today they are even given free, and now due to those drugs, children are living to be as old as 15 years. With this science and technology, who knows, maybe by the time they will be 25 years another type of drug will be discovered to help the child to live forever. So parents and children should not lose hope.

PLHIV support group member, Eastern

\section{HIV among Older Children}

As the first generation of children born HIV-positive is now surviving well into their twenties after having been on treatment for most of their lives, and as other young people become infected with HIV during childhood or adolescence, the qualitative study investigated some of the different barriers to HIV treatment and care faced by older children and adolescents. Community members were aware that children were increasingly surviving to know and understand the implications of their own status, and to value the importance of taking responsibility for their own treatment. Caregivers of adolescents and older children reported difficulties motivating the youth to maintain good treatment adherence, as they began to assert their independence and experience feelings of teenage rebellion and emotional extremes.

[Adherence is] no problem with smaller children because they don't have a say. But for elder children some will show signs of fatigue with medication. You can hear a child asking why he must take another dose and he's not feeling sick. We try to just persuade them but you never know if they may refuse drugs completely as they continue to grow up....

PLHIV support group member, Nyanza

Yes, adolescents are hard-headed. They say they are in a stage of development that the adult members also went through. Issues of abstinence don't make much sense to them. Convincing them to take tests is a big issue. For those on ARVs, who knows whether they adhere or not? They hardly share their experiences of ARVs with parents/caregivers, they want to keep their secrets to themselves.

PLHIV support group member, Nyanza

Participants also discussed the importance of acknowledging and responding to the growing sexuality of adolescents and addressing their risk behaviors. Caregivers reported difficulties communicating with adolescents about issues of treatment, adherence, and sexual behavior, and called for youth-friendly services to respond to the care and treatment needs of adolescents on ART and to make sure that they are counseled on sexual risk-taking. Whether they were infected perinatally or through sexual transmission, HIV-positive youth require sensitive counseling to address their own situations, including discussion of relationships, dating, and fertility choices, and to make sure that they are prepared to protect future sexual partners from exposure to HIV. 
HIV-positive children who attend school, including boarding schools, face an additional set of issues surrounding their HIV status. Like any adult trying to hide their HIV status, they may face difficulties taking their ART on time while still managing to conceal their drugs. If their status is known or suspected, other pupils may stigmatize them by avoiding them or subjecting them to verbal abuse. There was dissent among PLHIV support group members discussing how such HIV-related discrimination ought to be handled in schools: some argued that HIV-positive children should get special treatment, such as a daily serving of milk, while others argued that such isolating measures would only serve to increase children's exposure to stigma. Some CHWs and caregivers emphasized the importance of sensitizing teachers to be supportive of their HIV-positive pupils, including their treatment adherence support needs (e.g., the importance of timing and access to food and water) and the importance of maintaining confidentiality. However, they cautioned that disclosing a child's HIV status to a teacher should only be done with that child's participation and consent. Others suggested telling the teacher by attributing the child's special support needs to another medical condition.

Like this one of ours, another day he said he was written a letter by another girl being told "you are as ugly as a pig in the forest, you look like a dog," and other things. Other things are from the girl's parent. Maybe he/she explains to the child that when you see that, just know the child is sick. At times it becomes a difficult life.

PLHIV support group member, Eastern

If the infected child has grown thin or has skin infection, other children fear him/her. This makes him withdrawn and lonely because other children avoid him. They don't want to sit next to him, talk to him, touch him, or befriend him.

Community health worker, Nyanza

The teachers sympathize with them. But the fellow children despise them. Some do not even want to sit with them on the same desk. Other children fear them.

PLHIV support group member, Nyanza

We give food in the morning then give the medication before the child leaves for school. We give him some drugs to carry and take at school. We also make sure he carries water. Back at home in the evening, we give him the evening dose after supper. That's how we have been operating.

PLHIV support group member, Nyanza

Teachers should be told of a child who is on treatment so that they also provide care. ... they can be told the child has some disease and is taking medication but you don't specify it as HIV. ... you just tell the teacher the child is sickly and should not be given heavy duties, should not be heavily caned or made to run long distances. You can even say the child is hypertensive and needs polite talks and any other care that would not worsen the condition. Don't talk of HIV. Some of those teachers have long mouths and can even abuse the child referring to that condition.

PLHIV support group member, Nyanza 


\section{Hgrizons}

\section{Facility Barriers}

\section{Description of respondents}

To assess supply side barriers, health workers at the study sites were asked to complete a selfadministered survey assessing their knowledge, attitudes, training needs, and contact with HIV-positive children. A total of 103 health workers participated in the study. However, six health workers were subsequently excluded from the analysis as they belonged to cadres outside the scope of this study (nutritionists, records officer). Of the remaining 97 health workers included in the sample analyzed below, the distribution of respondents by cadre is shown below (see Table 15). The majority were from district level hospitals ( 40 percent), a quarter from tertiary hospitals ( 26 percent), and less than a fifth each from Mission hospitals (16 percent) and HIV care clinics (19 percent). Not all health workers provided responses to all questions, so totals for some questions may add up to less than 100 percent.

Table 15 Distribution of health workers by cadre who completed self-administered survey

\begin{tabular}{lc}
\hline Respondent cadre & \multicolumn{2}{c}{ Total } \\
& $\mathbf{n = 9 7}$ \\
& $\%$ \\
\hline Doctors & 4 \\
Clinical officers $^{+}$ & 11 \\
Nurses & 71 \\
Pharmaceutical technicians & 3 \\
Laboratory technicians $_{\text {Counselors }}$ & 3 \\
Unspecified & 3 \\
\hline
\end{tabular}

${ }^{+}$Clinical officers are an intermediate professional step between nurses and doctors, responsible for medical treatment at health facilities without doctors.

\section{Knowledge about pediatric HIV infection among health workers}

Knowledge about pediatric HIV among health workers was assessed by asking a series of questions on diagnosis of HIV infection in children, transmission of HIV from positive mothers to children, treatment with ARVs, disclosure, and counseling. Table 16 indicates the questions and their correct response rates. The need for more training is highlighted by low correct response rates, especially to questions about diagnosis of pediatric HIV infection, medication use for HIV and anemia or HIV and TB co-infection, vaccinations for symptomatic children, and mother-to-child transmission. A high proportion of nurses were unable to correctly answer all of the questions posed, and even the more highly trained doctors and clinical officers were unable to provide all correct responses. Reflecting their specific responsibilities, counselors were the best informed on pediatric HIV diagnosis, transmission of infection, and counseling issues. 
Table 16 Proportion of health workers who answered knowledge questions correctly, health care worker survey

\begin{tabular}{|c|c|c|c|c|}
\hline Knowledge question & Doctors & $\begin{array}{l}\text { Clinical } \\
\text { Officers }\end{array}$ & Nurses & Counselors \\
\hline $\begin{array}{l}\text { Test to diagnose HIV infection in children }<18 \text { months } \\
\text { of age } \\
\text { (Correct response: PCR) }\end{array}$ & $1 / 2$ & $\begin{array}{l}8 / 10 \\
(80 \%)\end{array}$ & $\begin{array}{l}55 / 69 \\
(61 \%)\end{array}$ & $3 / 3$ \\
\hline $\begin{array}{l}\text { Test to diagnose HIV infection in children > } 18 \text { months } \\
\text { of age }^{+} \\
\text {(Correct response: HIV ELISA) }\end{array}$ & $2 / 3$ & $\begin{array}{l}7 / 10 \\
(70 \%)\end{array}$ & $\begin{array}{l}47 / 70 \\
(51 \%)\end{array}$ & $3 / 3$ \\
\hline $\begin{array}{l}\text { Time for first PCR test to diagnose HIV infection in } \\
\text { children }<18 \text { months as per national guidelines }{ }^{+} \\
\text {(Correct response: } 6 \text { weeks) }\end{array}$ & $2 / 3$ & $\begin{array}{c}4 / 9 \\
(44 \%)\end{array}$ & $\begin{array}{l}35 / 67 \\
(52 \%)\end{array}$ & $3 / 3$ \\
\hline $\begin{array}{l}\text { Age when cotrimoxazole prophylaxis should be started } \\
\text { for HIV-exposed children } \\
\text { (Correct response: } 6 \text { weeks) }\end{array}$ & $2 / 3$ & $\begin{array}{l}6 / 10 \\
(60 \%)\end{array}$ & $\begin{array}{l}33 / 67 \\
(49 \%)\end{array}$ & $3 / 3$ \\
\hline $\begin{array}{l}\text { Zidovudine should not be given in anemia }{ }^{+} \\
\text {(Correct response: True) }\end{array}$ & $1 / 3$ & $\begin{array}{c}3 / 9 \\
(33 \%)\end{array}$ & $\begin{array}{l}16 / 63 \\
(25 \%)\end{array}$ & $0 / 3$ \\
\hline $\begin{array}{l}\text { Almost all children born to HIV-positive mothers will } \\
\text { acquire HIV from their mothers }{ }^{++} \\
\text {(Correct response: False) }\end{array}$ & $3 / 3$ & $\begin{array}{c}4 / 10 \\
(40 \%)\end{array}$ & $\begin{array}{l}55 / 71 \\
(77 \%)\end{array}$ & $3 / 3$ \\
\hline $\begin{array}{l}\text { A woman who is HIV-negative antepartum but acquires } \\
\text { HIV in the immediate postpartum period can transmit } \\
\text { HIV to her child through breastfeeding }{ }^{++} \text {(Correct } \\
\text { response: True) }\end{array}$ & $2 / 3$ & $\begin{array}{l}9 / 10 \\
(90 \%)\end{array}$ & $\begin{array}{l}46 / 71 \\
(65 \%)\end{array}$ & $3 / 3$ \\
\hline $\begin{array}{l}\text { Measles vaccine is contraindicated in symptomatic } \\
\text { pediatric HIV patients } \\
\text { (Correct response: True) }\end{array}$ & $2 / 3$ & $\begin{array}{c}1 / 7 \\
(14 \%)\end{array}$ & $\begin{array}{l}17 / 70 \\
(24 \%)\end{array}$ & $1 / 3$ \\
\hline $\begin{array}{l}\text { Efavirenz should be substituted for nevirapine in all } \\
\text { infants and children on ART and TB treatment }{ }^{++} \\
\text {(Correct response: False) }\end{array}$ & $2 / 3$ & $\begin{array}{c}4 / 9 \\
(44 \%)\end{array}$ & $\begin{array}{l}6 / 67 \\
(9 \%)\end{array}$ & $0 / 2$ \\
\hline $\begin{array}{l}\text { Stavudine suspension requires refrigeration }{ }^{++} \\
\text {(Correct response: True) }\end{array}$ & $1 / 3$ & $\begin{array}{c}3 / 9 \\
(33 \%)\end{array}$ & $\begin{array}{l}14 / 65 \\
(22 \%)\end{array}$ & $0 / 1$ \\
\hline $\begin{array}{l}\text { Abacavir can cause a potentially fatal hypersensitivity } \\
\text { reaction }^{++} \\
\text {(Correct response: True) }\end{array}$ & $3 / 3$ & $\begin{array}{l}3 / 10 \\
(30 \%)\end{array}$ & $\begin{array}{l}14 / 66 \\
(21 \%)\end{array}$ & $0 / 1$ \\
\hline $\begin{array}{l}\text { Child communication strategies during counseling } \\
\text { include make-believe play and drawing pictures } \\
\text { (Correct response: True) }\end{array}$ & $3 / 3$ & $\begin{array}{c}5 / 9 \\
(56 \%)\end{array}$ & $\begin{array}{l}40 / 66 \\
(61 \%)\end{array}$ & $2 / 2$ \\
\hline $\begin{array}{l}\text { Disclosure of a child's HIV status is recommended once } \\
\text { the child is able to understand and the parent/caregiver } \\
\text { gives consent }{ }^{++} \\
\text {(Correct response: True) }\end{array}$ & $3 / 3$ & $\begin{array}{c}7 / 9 \\
(78 \%)\end{array}$ & $\begin{array}{l}53 / 67 \\
(79 \%)\end{array}$ & $2 / 3$ \\
\hline
\end{tabular}

${ }^{+} \mathrm{HW}$ selected the correct answers from a choice of options

${ }^{++}$statements offered as true or false or don't know 


\section{Hgrizons}

Health providers were also asked about signs and symptoms that may indicate possible HIV infection in children under five years of age. Of the 94 health workers who provided responses, the most common answers were persistent diarrhea (mentioned by 63 percent of all health workers), very low weight for age (59 percent), having an HIV-positive parent (57 percent), delayed milestones (51 percent), and frequent hospitalization (50 percent). Less well-known signs indicating possible HIV infection were widespread scabies ( 5 percent), oral thrush in a one-week old baby (28 percent), and severe pneumonia (37 percent). It is of concern that across all of these questions, less than two-thirds of health providers were able to answer correctly, indicating a lack of awareness that poses a barrier to getting HIV-infected children into health care.

\section{Provider confidence in providing pediatric HIV services}

About three-quarters (74 percent) of all the health workers surveyed ( $2 / 4$ doctors; $9 / 11$ clinical officers; and 77 percent [54/70] of nurses) had worked specifically in child health clinics, pediatric wards, or outpatient departments - the departments in which children suspected to be HIV-positive are most likely to be encountered.

As Figure 5 shows, a significant proportion of these health providers did not feel confident in their abilities to provide HIV services for children. In line with their responsibilities, doctors and clinical officers indicated that they felt more comfortable providing clinical services than counseling services: 79 percent of doctors and clinical officers reported confidence in initiating ART, 67 percent in calculating pediatric medication dosage, and 69 percent in HIV disease staging in children. Clinical officers, who are often responsible for pediatric treatment at health facilities without medical doctors, were found to be less confident compared to doctors, highlighting the need for ongoing training with access to specialist consultations when required.

With regard to counseling services, about two-thirds of doctors and clinical officers felt confident providing HIV counseling (64 percent) and adherence counseling (67 percent) for children; only half felt confident disclosing the child's HIV status to the parents, and less than a third were comfortable disclosing to the child. This is of concern as doctors and clinical officers are often viewed as the health providers on top of the pyramid in health care, and their views are taken most seriously by patients and caregivers. In the case of other serious, life threatening, or terminal illnesses, it is usually the doctor who first discusses test results and diagnoses.

In HIV care services, nurses form the backbone of healthcare for patients and are most often assigned counseling tasks related to HIV testing, treatment adherence, side effects, and prevention. Less than half the nurses surveyed felt confident disclosing HIV status to children (20 percent), conducting pediatric disease staging (36 percent), calculating medication dosage ( 25 percent), providing adherence counseling (30 percent), and providing palliative care (40 percent). Only about half felt confident providing counseling related to HIV testing and disclosing the child's HIV status to parents (58 percent), indicating that further training and support is needed in these areas. More than three-quarters reported feeling confident about monitoring growth and development, a task that they have traditionally performed since long before the introduction of pediatric HIV services.

Counselors were the only cadre of health providers to report confidence in all the activities typically assigned to them, possibly due to the emphasis on counseling and confidentiality by HIV programs in the past several years. 
Figure 5 Health workers reporting confidence in providing pediatric HIV care services, healthcare worker survey

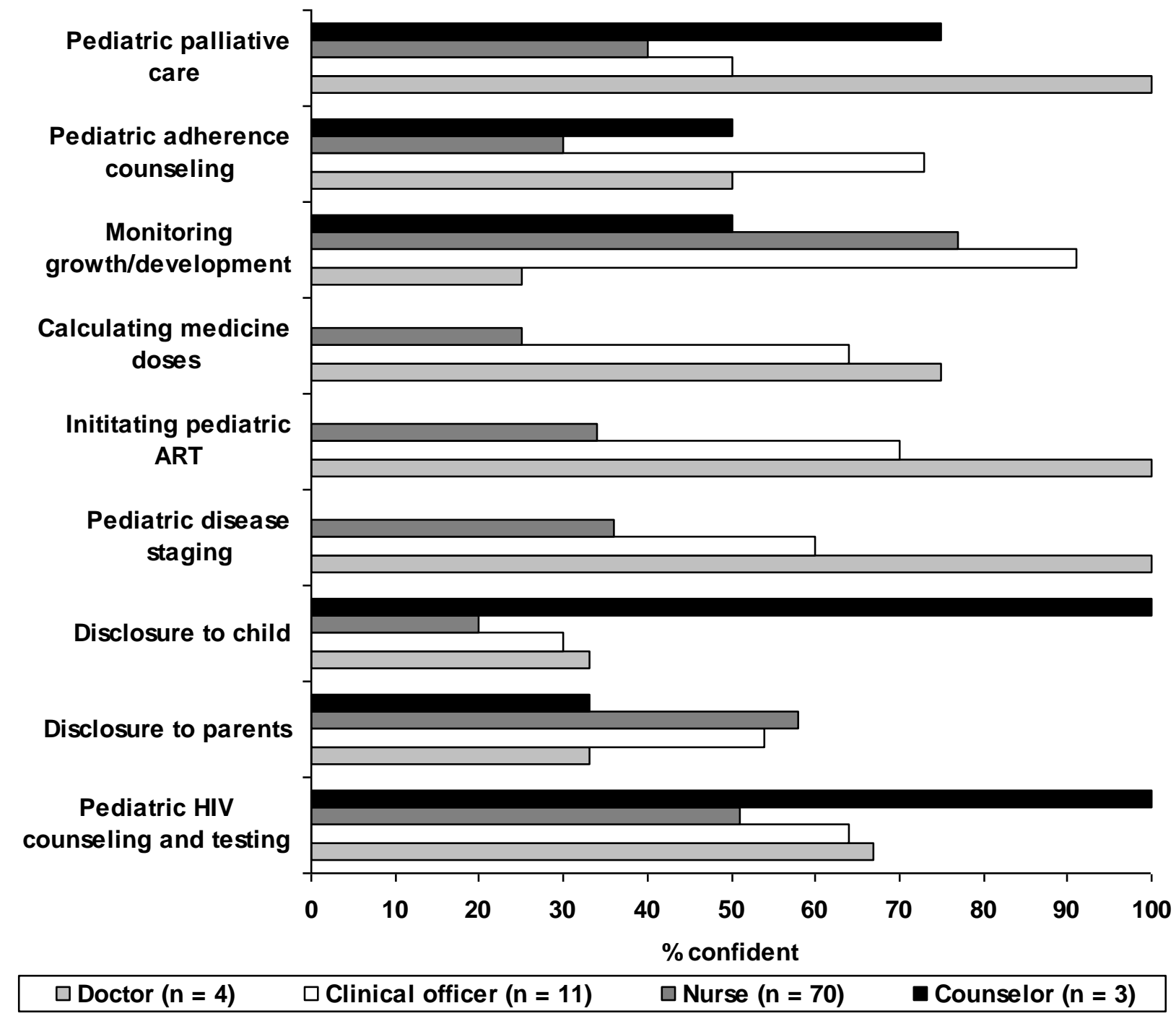

Note: Counselors not included in initiating pediatric ART and calculating medication doses.

Health workers were asked to report the three most challenging problems they encounter in providing pediatric HIV testing, treatment, and care. The most frequently-cited challenges in HIV testing included obtaining consent from the parent or caregiver to test the child, disclosing the child's HIV status to their parents or caregivers, and counseling caregivers about pediatric HIV infection. With regard to pediatric HIV treatment and care, the most frequently-cited challenges pertained to adherence to treatment, calculating medication dosage, food security, and poor follow-up. 


\section{Hgrizons}

\section{Provider training history and needs}

Health workers were asked about past training received on specific topics related to HIV infection in children and whether or not they felt the need for further training (see Table 17). It is particularly notable that among the four doctors surveyed, none reported having received training in OI prophylaxis in children, PMTCT, or integrated management of childhood illness (IMCI).

Similarly, among clinical officers and nurses, less than half had received training in HIV management, pediatric ART, and IMCI. Most nurses also did not receive training related to basic HIV counseling, child-specific counseling, and counseling around diagnostic testing. It appears that training for health providers is provided along vertical lines defined by job descriptions, without taking into account the need for overlapping skills in treatment and counseling when addressing patients.

Table 17 Training status and needs of health care providers, health worker survey

\begin{tabular}{|c|c|c|c|c|c|c|}
\hline \multirow{2}{*}{$\overline{\text { Topic }}$} & \multirow{2}{*}{ Training status } & \multicolumn{5}{|c|}{ Cadre } \\
\hline & & $\begin{array}{l}\text { Doctors } \\
(\mathrm{n}=4)\end{array}$ & $\begin{array}{l}\text { Clinical } \\
\text { officers } \\
(n=11)\end{array}$ & $\begin{array}{l}\text { Nurses } \\
(\mathrm{n}=70)\end{array}$ & $\begin{array}{c}\text { Counselors } \\
(n=3)\end{array}$ & $\begin{array}{c}\text { Laboratory } \\
\text { technicians } \\
(\mathrm{n}=3)\end{array}$ \\
\hline \multirow{2}{*}{$\begin{array}{l}\text { Complementary } \\
\text { IMCl/HIV }\end{array}$} & Received & $0 / 4$ & $3 / 11$ & $10 / 70$ & $0 / 3$ & - \\
\hline & Need further training & $2 / 4$ & $4 / 11$ & $46 / 70$ & $0 / 3$ & - \\
\hline \multirow{2}{*}{ РMTCT } & Received & $0 / 4$ & $4 / 11$ & $29 / 70$ & $2 / 3$ & - \\
\hline & Need further training & $2 / 4$ & $3 / 11$ & $32 / 70$ & $0 / 3$ & - \\
\hline \multirow{2}{*}{$\begin{array}{l}\text { Diagnostic } \\
\text { testing and } \\
\text { counseling }\end{array}$} & Received & $0 / 4$ & $2 / 11$ & $18 / 70$ & $3 / 3$ & - \\
\hline & Need further training & $2 / 4$ & $3 / 11$ & $19 / 70$ & $0 / 3$ & - \\
\hline \multirow{2}{*}{$\begin{array}{l}\text { Basic } \\
\text { counseling }\end{array}$} & Received & $0 / 4$ & $1 / 11$ & $22 / 70$ & $3 / 3$ & - \\
\hline & Need further training & $1 / 4$ & $4 / 11$ & $18 / 70$ & $0 / 3$ & - \\
\hline \multirow{2}{*}{$\begin{array}{l}\text { Child-specific } \\
\text { counseling }\end{array}$} & Received & $0 / 4$ & $1 / 11$ & $8 / 70$ & $0 / 3$ & - \\
\hline & Need further training & $1 / 4$ & $4 / 11$ & $35 / 70$ & $3 / 3$ & - \\
\hline \multirow{2}{*}{$\begin{array}{l}\text { Pediatric HIV } \\
\text { management }\end{array}$} & Received & $1 / 4$ & $4 / 11$ & $10 / 70$ & $0 / 3$ & - \\
\hline & Need further training & $3 / 4$ & $7 / 11$ & $45 / 70$ & $2 / 3$ & - \\
\hline \multirow{2}{*}{$\begin{array}{l}\text { Ol prophylaxis in } \\
\text { children }\end{array}$} & Received & $0 / 4$ & $4 / 11$ & 9/70 & $0 / 3$ & - \\
\hline & Need further training & $2 / 4$ & $3 / 11$ & $28 / 70$ & $1 / 3$ & - \\
\hline \multirow{2}{*}{ Pediatric ART } & Received & $2 / 4$ & $3 / 11$ & $8 / 70$ & $0 / 3$ & - \\
\hline & Need further training & $2 / 4$ & $7 / 11$ & $43 / 70$ & $2 / 3$ & - \\
\hline \multirow{2}{*}{ Dry blood spots } & Received & $0 / 4$ & $3 / 11$ & $17 / 70$ & $0 / 3$ & $2 / 3$ \\
\hline & Need further training & $1 / 4$ & $2 / 11$ & $19 / 70$ & $1 / 3$ & $2 / 3$ \\
\hline \multicolumn{2}{|l|}{ No training } & $2 / 4$ & $3 / 11$ & $13 / 70$ & $0 / 3$ & - \\
\hline
\end{tabular}




\section{Health workers' personal testing practices}

In order to assess health workers' attitudes toward HIV testing, health care workers were asked whether they and their children had been tested for HIV. Response rates to these questions were variable.

Seventy four percent of those responding (64/86) had been tested for HIV. While all responding doctors $(2 / 2)$ and a majority of clinical officers $(9 / 11)$ had been tested, only 70 percent of the responding nurses (45/64) reported being tested. Of those who reported having had an HIV test and having a spouse or regular partner $(\mathrm{n}=56)$, the vast majority (96 percent) had informed their partner about their test result.

Health workers were asked if they had tested any of their children for HIV. Of those who responded and had children $(n=68)$ only 34 percent reported that any of their children had been tested.

\section{Availability of service delivery guidelines}

Health workers were asked if they were aware of the specific government-issued guidelines on selected treatment and counseling topics available to assist with patient management, and whether or not they had read them. Overall, the availability of guidelines was reportedly good among those who responded: more than three-quarters of health workers reported having seen guidelines on voluntary counseling and testing (VCT) (87 percent, 78/90), clinical manual for ARVs (92 percent, 78/85), PMTCT (92 percent, 83/90), diagnostic testing and counseling (87 percent, 69/79), OI management (84 percent, 62/74), and homebased care (75 percent, 59/79).

Despite knowing that the guidelines were available, many health workers reported not having read them. About half of the health workers had read the guidelines on VCT (58 percent), HIV testing in clinical settings ( 56 percent), and home-based care (51 percent). Among doctors and clinical officers, 77 percent (10/13) had read the clinical manual on ARVs, 62 percent (8/13) had read the PMTCT guidelines, and 67 percent (8/12) had read guidelines on OI management. Among nurses, 75 percent (46/61) had read the PMTCT guidelines, 52 percent (22/42) had read about HIV testing in clinical settings, and 64 percent $(34 / 53)$ had read guidelines on OI management. 


\section{Hgrizons}

\section{Discussion}

This research was motivated by statistics showing the wide gap between pediatric and adult uptake of ARVs. While other studies have focused on facility-based barriers to supplying pediatric ARVs, the primary purpose of this study was to respond to the question, "If you build it, will they come?"reflecting recent awareness that equipping facilities to supply pediatric HIV services is only the first part of a process, and that much work remains to be done to encourage community members to use these services.

The study found qualitative and in-depth methodologies particularly crucial in understanding a sensitive and multi-layered topic such as pediatric HIV disease. Even when pediatric HIV care and treatment services are available in a community, this research demonstrates many obstacles impeding community access to these services. This section summarizes the barriers identified in the study and makes some suggestions as to how they can be addressed.

\section{Barriers to Pediatric HIV Care}

\section{Cost}

In this study, the costs of seeking healthcare were cited as barriers to accessing pediatric HIV testing and treatment services, especially in Nyanza province. Even though the cost of providing ARV drugs is theoretically free (covered by government and donor sources), potential clients still have to find money to pay for the high costs of transport, consultation fees, and drugs to treat OIs, in addition to the opportunity costs of time spent seeking care instead of earning money to feed and support other household members. Research participants reported that they had delayed or deferred care for their pediatric age child as a result of all these costs.

Poverty is a complex problem to address, but its deterrence to care could be alleviated somewhat with mobile and home-based services. For example, door-to-door HIV testing is already being piloted in certain parts of Kenya, and this could be tried in study sites as well, saving families transport and time costs. Some countries are also experimenting with door-to-door ARV service delivery, and these could be considered. Programs to provide food may be particularly urgent, but may be best linked to food production to enable sustainability over the long run. In Kenya, these types of programs are already being implemented, for example by AMPATH at Moi University in Western Kenya.

\section{Health-seeking behaviors and cultural beliefs}

Discrepancies between the quantitative household survey and the qualitative FGDs revealed some key insights into health-seeking behaviors. While nearly all household survey respondents said that they had utilized modern medical clinic facilities, FGDs revealed considerable interest in and utilization of traditional and faith healers, especially in Nyanza and Eastern provinces. Research participants indicated that convenience and affordability are factors that encourage them to seek traditional remedies as the first port of call. Health care providers are sometimes at a loss about how to respond to clients who utilize both traditional healers and modern clinic care. Thus programs need to explore ways to partner with this cadre 
of health providers and inform and advise health care providers on how to respond convincingly to caregivers who opt for traditional and faith healing.

\section{Stigma}

The household survey revealed the continuing high prevalence of stigmatizing attitudes in the community toward people who are living with HIV, holding them responsible for the transmission of the virus to their young children, and associating their status with promiscuity and shame. Stigma faced by adults manifests as a barrier for their children's care, representing a further victimization for this highly vulnerable group. Because pediatric HIV care requires frequent hospital visits, caregivers must confront and overcome these barriers repeatedly. Stigma was cited as one of the main reasons that HIV-positive parents had delayed seeking care, impeding their ability to disclose their HIV status (including permitting home visits from community health workers) and to seek care for their children. Programs need to recognize the tremendous obstacle that stigma presents to potential clients and seek new ways to configure services that avoid singling out those who are HIV-positive for special treatment.

The household survey and focus groups also revealed some promising trends indicating that community members are willing to house an HIV-positive child in their home, be responsible for their treatment, and allow their children to have HIV-positive schoolmates. Programs need to begin to build on the goodwill that is emerging in the community to find new ways to provide support to parents and caregivers in the care of their children.

\section{Knowledge about pediatric HIV}

While survey data showed that virtually all respondents were aware of the basics of HIV, knowledge of how it was transmitted to children and the indications for HIV testing was superficial. With a lack of indepth information about pediatric HIV disease evident in the community, fears and misconceptions still prevail: many community members believed that once a child is past three years of age, they cannot be HIV-positive, and there is therefore no need to test. Only half of respondents were aware that pediatric ARVs are a lifelong commitment. These findings suggest there is a need to inform caregivers about HIV disease in children, so that adequate care can be quickly sought.

Results suggest that community members are more inclined to suspect HIV infection as a result of familial and behavioral indications of testing, while health workers and community health workers more commonly focused on signs and symptoms of physical health. This difference indicates the need for health workers and community health workers to be sensitive to the concerns and motivations of their clients, while also increasing client and community education on common medical signs and symptoms to watch out for.

The study also found that the mass media and health care workers were the most cited sources of information about HIV. This suggests that there is a need to greatly expand the use of mass media, as it is an efficient way to communicate to broad audiences. Relying on health workers as a source of information may take longer to reach large numbers of people, but represents a more personalized contact, as long as health workers are appropriately trained. 


\section{Hgrizons}

\section{Awareness of local pediatric HIV treatment options}

Since this study was specifically designed to take place in areas in which pediatric HIV testing and treatment services were available within a distance of $5 \mathrm{~km}$, it is especially disappointing that awareness of the services was fairly low-less than two-thirds of caregivers were aware of a specific facility to which they could take a child for testing or treatment. However, it is promising that approximately two-thirds of caregivers were already aware that medication for treating children was now available for free in public sector facilities in Kenya. Yet caregivers were worried that the free treatment could be withdrawn, and wondered what would happen in such a case. These findings suggest a need to publicize pediatric HIV care services and to directly address caregivers' concerns regarding the sustainability of free treatment.

\section{Child's HIV status as a window to parents' status}

This study also revealed the importance of acknowledging the links between HIV testing for parents and their children. Parents, especially mothers, expressed fear that having a child who is found to be HIVpositive will reveal their own HIV status, exposing them to stigma and allegations of promiscuity or unfaithfulness, and forcing them to face up to their own treatment needs. Programs need to address these concerns directly and convince wary caregivers that it is in their interest to know their HIV status, as well as that of their child.

The household survey revealed that approximately half of respondents had been tested for HIV (as adults), with females almost twice as likely to have been tested as males, and often also better informed. Since at least half of respondents did not know whether their partner had been tested, there remain opportunities for programs to promote VCT among adults as well as children. Programs need to develop opportunities through which to address male caregivers, whose testing behaviors are lagging behind their female counterparts. The survey data show promising starting points: caregivers resided in relatively egalitarian households, with considerable autonomy in healthcare decision-making; fathers seemed to know a fair amount when it came to the well-being of the children. Caregivers can officially invite fathers as partners in pediatric AIDS testing and treatment programs, so that they too can learn about this infection. Fathers' clinics or similar male-centered activities can offer an opportunity for further education. Utilizing male health care workers and community health workers are additional strategies for reaching out to men more effectively.

\section{Fatalism, fear, and loss of hope}

Attitudinal barriers still present a major obstacle that deters parents and caregivers from seeking pediatric HIV testing and treatment. Although some research participants were aware of tremendous health gains experienced by children on ARVs, the widespread belief that a child who is HIV-positive is a "lost cause" still persists. Fatalistic attitudes still equate HIV with death, especially among young and sickly children, and many participants in the qualitative research reported reluctance among community members to invest resources in such children under such pessimistic scenarios.

Programs need to continue to encourage caregivers, for example by showing successful outcomes of children who have used treatment. Just as the recent treatment campaign in Kenya encouraged adults to seek treatment, a similar campaign can be implemented to encourage caregivers to bring children for treatment. Since evidence suggests that some of these negative attitudes may be originating with health 
care providers, it is also important to make sure that providers too have accurate information so that they can impart the correct knowledge to caregivers and be sensitive to their needs. It is also important that healthcare providers be educated in interpersonal communication skills, so that they can communicate empathetically and encourage caregivers.

\section{Treatment difficulties}

FGDs revealed that there remain difficulties inherent in administering pediatric HIV treatment. It was clear that pediatric adherence required highly committed caregivers. Community health workers emphasized the importance of follow-up care and adherence support through the clinics. Treatment literacy programs would go a long way toward helping caregivers deal with these problems. Simple measuring devices that can help caregivers deal with calibration problems should be made more widely available. Caregivers need help on what to tell other children and where to keep the medicines safe, a major challenge as many live in single-room dwellings with limited places to secure medications. Caregivers also need help internalizing the fact that the current drugs are to be taken for life, until another option is developed. This would minimize those who may decide to stop giving the child medicine when the child looks better.

\section{Specific barriers for adolescent children}

With the first generation of children born HIV-positive now surviving well into their 20s, a new range of issues must be addressed. Children and adolescents who have lived all their lives with HIV, looking after their health and dealing with the demands of treatment, now grapple with new issues as they forge their own independent lives.

Programmatic opportunities to respond to these concerns include creating youth-friendly environments and support groups for young people, where adolescents can feel comfortable. There is a need for adolescent-friendly educational activities and materials that can help them deal with emerging concerns such as sexuality, safer sex, self esteem, and peer pressure. Such programs should also educate caregivers on how to support their adolescent children, for example when they ask about medication, addressing their emerging sexuality, and coping with the physical and social demands of school life. Parents of adolescent children may also need support and guidance on issues including dealing with teachers while maintaining the dignity of the child, addressing the uncomfortable issue of how the child got infected, and how to talk about their own sexuality.

\section{Quality of care}

Displeasure related to quality of care and concerns about confidentiality of health services reportedly deterring community members from seeking care for children. It is imperative that clinics address this concern. Unfriendly provider attitudes may be a result of many factors, including the fact that providers themselves are also under extreme pressure to cope with a heavy workload and issues for which they have not been adequately prepared. Health facilities need to equip providers with appropriate skills, supplies, and a supportive environment, so that they can offer their services in a humane manner. This is especially important in the context of HIV, where there are already many caregiver barriers to be overcome before care can be obtained, and where timely care of children is especially important. Programs to address this 


\section{Hgrizons}

concern are particularly needed in Nyanza province, where HIV prevalence is the highest, and the number of pediatric age patients is also high.

\section{Missed opportunities for client-provider communication about pediatric HIV}

Survey responses indicated that, among community members with children under the age of five years who received ANC at their last pregnancy, almost a third had not been told about PMTCT. This finding suggests a missed opportunity for providers to communicate with mothers about the possibilities of perinatal HIV transmission and appropriate care and precautions for mother and child during pregnancy and infanthood. Especially in light of low levels of knowledge about pediatric HIV transmission and the availability of testing and treatment reflected in the survey, interactions between health providers and mothers during the antenatal period represent an opportunity to communicate about these issues during a time when women may be particularly receptive. Further opportunities to communicate with caregivers about the possibility of HIV testing for older children also appear to be underutilized.

These findings suggest the importance of emphasizing opportunities for health workers to educate their clients about pediatric HIV. Interventions to foster improved client-provider communication might include the introduction of job aids to help health workers remember to discuss pediatric HIV, specially designed materials (such as posters or leaflets) to educate and motivate women attending health facilities to think about the issues, or group educational briefing sessions in the waiting area.

\section{The vital role of community health workers}

The study revealed the crucial role played by CHWs as an important link between community members and health facilities, responsible for managing varied aspects of HIV disease management, from the identification of those who could benefit from testing to following up with those who may have defaulted on treatment. Emphasizing the responsibilities of CHWs with regard to pediatric HIV, such as making referrals for pediatric testing and supporting caregivers of children known or suspected to be HIVpositive, requires skills strengthening, ongoing training and support, and further elevation of their role. Since early identification and referral is so crucial to successful pediatric HIV management, there are great benefits to be made by reinforcing the training and support of this important cadre in pediatric HIV management. With further appropriate training, CHWs would also be well placed to offer communitylevel counseling and follow-up support on drug adherence and nutrition. This approach would help to circumvent community level barriers to care such as poverty and stigma, as well as ease congestion at secondary and tertiary levels of care.

\section{Health workers' low knowledge and confidence in providing pediatric HIV care}

The mini-survey among facility-based health workers revealed many gaps in knowledge and confidence regarding the provision of pediatric HIV testing, care, and treatment, including pediatric HIV diagnosis protocols, drug management, and child counseling. While not all types of health workers (including doctors, clinical officers, nurses, technicians) would necessarily be expected to be involved in all aspects of pediatric HIV management, given the high HIV prevalence rates in Kenya and the need for rapid scaleup of pediatric HIV services, these weaknesses remain notable. At the very least, all health workers working in pediatric departments (including routine growth monitoring clinics) ought to have knowledge 
of pediatric HIV testing, treatment, counseling, and care issues so as to be able to counsel parents and caregivers accurately and appropriately, facilitating speedy referrals and timely treatment. These data highlight the urgent need for scaling-up health worker training on pediatric HIV, including addressing client-provider communication skills and counseling for both adults and children. Outside of pediatric clinics, other health workers also responsible for referring children for HIV testing and treatment may include staff of outpatient departments and antenatal clinics, who should also be trained on communication and what signs and symptoms to look out for.

\section{Structural barriers}

Other challenges hampering pediatric HIV service delivery revealed by this study included limited physical space and staff numbers assigned to pediatric HIV care, resulting in long waiting times and limited privacy. Further logistical challenges included unreliable systems for obtaining PCR test results off-site, resulting in long waiting time for test results. The inability of the planned research to explore structural issues through health facility checklists and service statistics also indicates a need to strengthen routine systems for collection and management of facility data. All these challenges significantly reduce the capacity of health workers to offer quality care to their clients, a factor that in turn increases community barriers to uptake of pediatric HIV care. These data suggest that interventions aimed at streamlining and strengthening management aspects of pediatric HIV care are needed.

\section{Health management information system}

This study discovered that existing data collection systems focusing on pediatric HIV care and management were uniformly weak. A health management information system needs to be established at the facility level, to enable the collation of information at district and provincial levels, such as the number of children receiving HIV testing and treatment, which is not currently readily available.

\section{Programmatic Recommendations}

This study provides important insights into barriers to care for HIV-positive children in Kenya and programmatic guidance to address these barriers. Key programmatic recommendations include the following:

- Augment community awareness activities aimed at educating and supporting parents and caregivers of children, to inform them about pediatric HIV disease and expand uptake of available services for pediatric testing and HIV care. Community interventions should include stigma reduction activities, as stigma emerged in the study as a major barrier to seeking care for children. Additionally, community interventions should address cultural and religious beliefs in the community that prevent people from accessing timely care. Programs should consider strategies that would maximize the impact of mass media communication methods, which were cited as the main source of information in the community survey.

- Decentralize HIV testing and ART services to bring services closer to parents and caregivers of children, to reduce costs related to travel and time away from work. Programs may consider utilizing mobile clinics or the services of trained CHWs. 


\section{Hgrizons}

- Strengthen the capacity of health care workers so they can provide quality care to parents and caregivers of children and make appropriate pediatric referrals.

- Support family-based HIV testing approaches so HIV-positive family members can be identified and offered timely care; examine strategies to reach HIV-positive adolescents and young adults.

\section{Next Steps: Intervention Development}

The results of this study have been disseminated widely to maximize its utilization. Study results were shared with the Project Advisory Committee and other stakeholders in Kenya, to distill findings into recommendations for interventions. Population Council has begun to issue sub-awards to the study partners to develop and implement site-specific interventions to encourage uptake of pediatric care and treatment services. The interventions include community awareness activities to educate and support caregivers, inform them about available services, and reduce stigma. Study partners are also working to strengthen the capacity of health care workers, support family HIV testing, and explore strategies to reach HIV-positive adolescents and young adults. The research has also advised a new project that will assess different pediatric testing strategies, and has further highlighted the importance of concerted work to address stigma. 


\section{References}

African Population and Health Research Center. 2002. Population and Health Dynamics in Nairobi's Informal Settlements. Nairobi: African Population and Health Research Center.

ANECCA. 2005. Early Diagnosis of Pediatric HIV Infection in Sub-Saharan Africa: Advocacy Statement. African Network for the Care of Children Affected by HIV/AIDS.

Central Bureau of Statistics [Kenya] et al. 2004. Kenya Demographic and Health Survey, 2003. Nairobi, Kenya; Calverton, Md., USA, Central Bureau of Statistics: Ministry of Health; ORC Macro.

Cherutich, P. 2006. "Progress in pediatric ART in Kenya," Concretizing Pediatrics, Adolescent and Adult ART Scale-up: 4th National Consultative Conference on Antiretroviral Treatment, Nairobi.

deGennaro, V. and P. Zeitz. 2005. Treat the Children: Accelerating Action for Universal Antiretroviral Treatment for Children in Resource-Limited Countries by 2010. Washington DC: Global AIDS Alliance.

Eley, B., J. Nuttall, et al. 2004. "Initial experience of a public sector antiretroviral treatment programme for HIV-infected children and their infected parents," South African Medical Journal 94(8): 643-6.

Koech, E. 2006. "Current status of ART in Kenya," Concretizing Pediatrics, Adolescent and Adult ART Scale-up: 4th National Consultative Conference on Antiretroviral Treatment, Nairobi.

Luo, C. 2005. “Access to ARV \& treatment-The big picture," Paediatric AIDS Treatment for Africa (PATA) Conference, Cape Town.

Matida, L.H. et al. 2006. "Impact of free and universal access to antiretroviral treatment on the survival among Brazilian children with AIDS," XVI International AIDS Conference, Toronto, Canada.

Mbewe, M. et al. 2006. "Children enrolled in a public HIV care and treatment program in Lusaka, Zambia: rapid scale-up and first-year clinical outcomes,” XVI International AIDS Conference, Toronto, Canada.

NASCOP. 2005a. AIDS in Kenya (7th edition). Nairobi, National AIDS and STI Control Programme, Ministry of Health [Kenya].

NASCOP. 2005b. Guidelines for Antiretroviral Drug Therapy in Kenya (3rd edition). Nairobi, National AIDS and STI Control Programme, Ministry of Health [Kenya].

NASCOP/CDC. 2006. "Early infant diagnosis of HIV," presented by Mildred Mudany, PMTCT Stakeholders' meeting, CDCNairobi, December 19, 2006.

Office of the United States Global AIDS Coordinator. 2004. The President's Emergency Plan for AIDS Relief: U.S. Five Year Global HIV/AIDS Strategy. Washington DC: Office of the United States Global AIDS Coordinator.

Olson, D. et al. 2006a. "Anti-retroviral therapy (ART) outcomes in children < 13 years of age in resource-poor countries (RPCs): a Médecins sans frontières (MSF) cohort," XVI International AIDS Conference, Toronto, Canada.

UNAIDS. 2006. 2006 Report on the Global AIDS Epidemic. Geneva: UNAIDS.

UNICEF. 2005. The Global Campaign on Children and AIDS: Unite for children, Unite against AIDS. New York: UNICEF.

van Kooten Niekerk, N.K. et al. 2006. "The first 5 years of the family clinic for HIV at Tygerberg Hospital: family demographics, survival of children and early impact of antiretroviral therapy," Journal Tropical Pediatrics 52(1): 3-11.

Watson, D.C. and J. Farley. 1999. "Efficacy of and adherence to highly active antiretroviral therapy in children infected with human immunodeficiency virus type 1," Pediatric Infectious Disease Journal 18(8): 682-689.

World Health Organization. 2003. Treating 3 million by 2005: making it happen: the WHO strategy: the WHO and UNAIDS global initiative to provide antiretroviral therapy to 3 million people with HIV/AIDS in developing countries by the end of 2005. Geneva: World Health Organization. 


\section{Hgrizons}

\section{Appendix: Data Collectors and Supervisors}

George Odero Auko

Tabitha Awino

Dan Mark Awour

Claris Ayieta

Amalemba Kibidi

Michael Kibogo

Kimuma Kosida

Grace Magomere

Agnes Mbaabu

Ann Stella Mbwiria

Lydia Mugure

Cornelius Mutangili

Nancy Mutiga

Francis Nganga Ngugi

Dominic Njeru Njue

Roselyne Nthiga

Christine Nyambura

George Odingo

Rael Okiya

Eunice Olawo

Wilkister Ombidi

Mutuma Ringera

Olive Shume

Secret Siku

Jacinta Waira

Evelyn Weje 


\section{Hgrizons}

Horizons is a global operations research program designed to:

- Identify and test potential strategies to improve HIV/AIDS prevention, care, and support programs and service delivery.

- Disseminate best practices and utilize findings with a view toward scaling up successful interventions.

\section{(2) Population Council}

Horizons is implemented by the Population Council in collaboration with

- International Center for Research on Women (ICRW)

- International HIV/AIDS Alliance

- PATH

- Tulane University

- Family Health International (FHI)

- Johns Hopkins University

For more information, please contact:

Horizons Program, Communications Unit 4301 Connecticut Avenue, NW Suite 280 Washington, DC 20008 USA

Tel: 202-237-9400

Fax: 202-237-8410

Email: horizons@popcouncil.org www.popcouncil.org/horizons 